NBER WORKING PAPER SERIES

\title{
EXPECTATIONS OF EQUITY RISK PREMIA, VOLATILITY AND ASYMMETRY FROM A CORPORATE FINANCE PERSPECTIVE
}

\author{
John R. Graham \\ Campbell R. Harvey \\ Working Paper 8678 \\ http://www.nber.org/papers/w8678
NATIONAL BUREAU OF ECONOMIC RESEARCH
1050 Massachusetts Avenue
Cambridge, MA 02138
December 2001

\begin{abstract}
We thank the Financial Executives International (FEI) executives who took the time to fill out the surveys. We thank Alon Brav, Magnus Dahlquist, Ron Gallant, Jim Smith, Paul Soderlind and Bob Winkler for their helpful comments and the participants at the NBER Corporate Finance Summer Workshop. Krishnamoorthy Narasimhan provided research assistance. This research is partially sponsored by FEI but the opinions expressed in the paper are those of the authors and do not necessarily represent the views of FEI. Graham acknowledges financial support from the Alfred P. Sloan Research Foundation. The views expressed herein are those of the authors and not necessarily those of the National Bureau of Economic Research.
\end{abstract}

(C) 2001 by John R. Graham and Campbell R. Harvey. All rights reserved. Short sections of text, not to exceed two paragraphs, may be quoted without explicit permission provided that full credit, including (C) notice, is given to the source. 
Expectations of Equity Risk Premia, Volatility and Asymmetry from a Corporate Finance Perspective John R. Graham and Campbell R. Harvey

NBER Working Paper No. 8678

December 2001

JEL No. G1, G3

\begin{abstract}
We present new evidence on the distribution of the ex ante risk premium based on a multi-year survey of Chief Financial Officers (CFOs) of U.S. corporations. Currently, we have responses from surveys conducted from the second quarter of 2000 through the third quarter of 2001 . The results in this paper will be augmented as future surveys become available. We find direct evidence that the one-year risk premium is highly variable through time and 10-year expected risk premium is stable. In particular, after periods of negative returns, CFOs significantly reduce their one-year market forecasts, disagreement (volatility) increases and returns distributions are more skewed to the left. We also examine the relation between ex ante returns and ex ante volatility. The relation between the one-year expected risk premium and expected risk is negative. However, our research points to the importance of horizon. We find a significantly positive relation between expected return and expected risk at the 10-year horizon.
\end{abstract}

John R. Graham

Fuqua School of Business

Duke University

Durham, NC 27708
Campbell R. Harvey

Fuqua School of Business

Duke University

Durham, NC 27708

and NBER

Tel: 919-660-7768

Fax: 919-660-8030

cam.harvey@duke.edu 


\section{Introduction}

The current market capitalization of U.S. equities is approximately $\$ 10$ trillion. A shift in the equity risk premium by just one percent could add or subtract $\$ 1$ trillion in market value. In addition, corporate investment decisions hinge on the expectations of the risk premium (via the cost of capital) as do both U.S. and international asset allocation decisions. Therefore, it is important for financial economists to have a thorough understanding of the expected risk premium and the factors that influence it.

The expected market risk premium has traditionally been estimated using longterm historical average equity returns. Using this approach, in December 1999, the arithmetic average return on the S\&P 500 over and above the U.S. Treasury bill was reported by Ibbotson Associates (2000) to be 9.32\%. This is an extraordinarily high risk premium - though it seems to have influenced the views of a great many academics [Welch (2000)]. Fama and French (2001) conclude that average realized equity returns are in fact higher than ex ante expected returns over the past half century because realized returns included "large unexpected capital gains". If this is true, then using historical averages to estimate the risk premium is misleading.

We use a different approach to estimate the expected risk premium and offer a number of new insights. We base our estimate on a multiyear survey of Chief Financial Officers (CFOs), designed to measure their expectations of risk premia over both short and long horizons. Our survey is unique in that we obtain a measure of the entire risk premium distribution, rather than just the expected value (mean). That is, our survey captures both market volatility and asymmetries implicit in the respondents' probability distributions. In addition, we shed light on how recent stock market performance impacts the ex ante risk premium, volatility and asymmetries. We also study the relation between expected risk and expected return. 
There are many methods to estimate the equity risk premium and we can not tell which method is the best - because the variable of interest is fundamentally unobservable. The average of past returns is the method with the longest tradition. However, there are other time-series methods that use measures like dividend yields to forecast and short-horizon premia. These models are difficult to estimate and often structurally unstable [see Garcia and Ghysels (1999)].

There is considerable recent interest in what might be referred to as the implied method. There are two streams of this research. The original is based on the work of Black and Litterman $(1990,1991)$ and French and Poterba (1991). They argue that one can use investment weights to determine the equilibrium expected returns on equities as well as other assets. Graham and Harvey (1996) use a variant of this method to study the time-series behavior of equity risk premia implicit in the asset allocation recommendations of investment advisors.

A second approach uses fundamental data to deduce risk premia. Gebhardt, Lee and Swaminathan (2000) use firm level cash flow forecasts to derive an internal rate of return, or cost of capital, given the current stock price. Fama and French (2001) study the risk premia on the S\&P 500 from 1872-2000 using fundamental data. They argue that the ex ante risk premia is much lower than the historical average, between $2.55 \%$ and $4.32 \%$ for $1951-2000$. Ibbotson and Chen (2001) estimate a long-term risk premium between 4 and $6 \%$.

The final approach to estimate the equity risk premium category directly measures investor's and analyst expectations using survey methods. For example, Welch (2000) analyzes the views of financial economists. Fraser (2001) and Harris and Marston (2001) consider the evidence from financial analysts.

We, instead, survey CFOs. We think that this approach has several advantages. First, one could argue that the financial economists are not directly connected to the allocation decisions in the economy - either capital allocation (financial investment decisions) or real allocation (choosing real investment projects). 
CFOs, in contrast, are directly involved their firms' financial and real allocation decisions.

Second, biases in analysts' earnings expectations are well documented. Claus and Thomas (2001) use analysts' earnings expectations to derive an estimated market risk premium of $3.4 \%$. However, to obtain a risk premium this low they dampen the analysts' earnings growth projections for earnings more than five years in the future. When growth is not dampened, Harris and Marston (2001) find an implicit risk premium of $9.2 \%$ in 1998. More to the point, Brav and Lehavy (2001) show that analysts' target stock prices are also biased upward. Brav and Lehavy find that analysts' target prices predict a $22 \%$ average annual increase in stock prices from 1997-1999, while realized returns average only $15 \%$. In contrast, there is no reason to think that CFOs are biased in their view of the market equity premium.

The CFOs determine the hurdle rate for their firm's investments, and presumably, the equity risk premium plays an important role. Indeed, the evidence in Graham and Harvey (2001) indicates that three-fourths of firms use the capital asset pricing model (CAPM) of Sharpe (1964) and Lintner (1965) to establish their cost of capital. The equity risk premium is a critical input into the CAPM.

Our paper offers much more than a survey of CFO's expectations for the market. Our survey is multiyear and rich with additional information. We ask CFOs about their expectations of market performance over both one and 10-year horizons. We ask questions designed to determine their assessment of market volatility. These questions allow us to deduce each CFO's view about the distribution for the market risk premium, and we can observe how the shape and location of these distributions vary with market conditions.

The temporal dimension distinguishes our work from most previous survey work. We are able to address issues such as whether volatility and the risk premium are positively correlated through time. We are able to determine whether 
recent stock market performance changes expected returns. The interplay of recent equity performance and volatility expectations allows us to say something about asymmetric volatility. Our survey even allows us to deduce a measure of ex ante skewness.

While the surveys are anonymous, we have information on each respondent's industry, size by revenue, number of employees, headquarters location, ownership and percentage of foreign sales. We use this information to see if there are systematic differences in expectations based on firm characteristics.

Importantly, this is on-going research. We have conducted surveys representing over 1,100 total responses, from the second quarter of 2000 through the third quarter of 2001. We plan to update this paper as new surveys are conducted.

The results indicate that the one-year risk premium averages between 0.1 and 2.5 percent depending on the quarter surveyed. The 10-year premium is much less variable and ranges between 3.6 and 4.7 percent. We find that the CFOs' assessment of market volatility is much lower than popular alternative measures, strongly suggesting that CFOs are very confident in their opinions (i.e., their individual distributions for the market risk premium are tight).

We also find that the recent performance of the S\&P 500 has a significant effect on the short-term expected risk premium as well as forecasted volatility. Recent stock market performance also has a pronounced effect on CFO's ex ante skewness. In general, when recent stock market returns have been low, the expected risk premium is low, its distribution has a relatively fat left tail, and expected market volatility is high. Finally, we document a negative ex ante relation between expected returns and expected volatility at the one-year horizon and a positive relation at the 10-year horizon. Our results support the notion of a positive tradeoff between risk and expected return - but only at longer horizons. 
The paper is organized as follows. The second section details the methodology and the sampling procedure. The results are presented in the third section. An analysis conditional on firm characteristics is outlined in the fourth section. Some concluding remarks are offered in the final section.

\section{Methodology}

\subsection{Design}

The quarterly survey project is a joint effort with the Financial Executives International (FEI). FEI has approximately 14,000 members that hold policymaking positions as CFOs, treasurers, and controllers at 8,000 companies throughout the U.S. and Canada. Every quarter, Duke University and the FEI poll these financial officers with a one-page survey on important topical issues (Graham, 1999). The usual response rate for the quarterly survey is $5 \%-8 \%$.

The history of the survey instrument appears on the Internet at the address http://www.duke.edu/ charvey/Research/indexr.htm. Exhibit 1 details the exact questions that we asked regarding the equity premium.

\subsection{Delivery and response}

The survey is administered by a third-party data processing firm (Office Remedies Inc.). FEI faxes out approximately 4,000 surveys to a sample of their membership. The executives return their completed surveys by fax to the thirdparty data vendor. Using a third party ensures that the survey responses are anonymous. Although we do not know the identity of the survey respondents, as mentioned previously, we do know a number of firm-specific characteristics, as discussed below.

The surveys analyzed in this paper were distributed on the following days: June 6, 2000; September 7, 2000; December 4, 2000; March 12, 2001; June 7, 2001 
and September 10, 2001. In each case, the survey contained information about the yield on the 10-year Treasury bond at the close of the previous business day, and the respondents were given approximately five business days to return the survey. The date and time the survey is received is recorded on the survey. This allows us to examine if recent equity returns impact the CFOs' responses when they fill out the survey. Two-thirds of the surveys are usually returned within two business days.

We also conducted a survey at the North Carolina CFO Symposium (also sponsored by FEI) on August 22, 2000. In this case, we were able to obtain a response from nearly every executive in the room. By comparing these responses with the faxed quarterly survey responses, we are able to examine whether the response rate on the quarterly survey affects the CFO predictions about the equity market risk premium. (For example, perhaps predominantly "optimists" respond to the quarterly survey.) The North Carolina CFO survey also gathered some additional information about the 10-year risk premium not found on the quarterly surveys. We find that the responses for the North Carolina CFO survey are consistent with those from the quarterly survey. We integrate the responses from this survey into our main results. In our graphical analysis, we highlight this particular survey with a different symbol. ${ }^{1}$

\subsection{The survey instrument and summary statistics}

The risk premium questions are a subset of a larger set of questions in the Duke-FEI quarterly survey of CFOs. Copies of the surveys can be found on the Internet.

We ask respondents for their one- and 10-year forecasts of the S\&P500 given the current 10-year Treasury bond rate (see Exhibit 1). The CFOs also complete 
the following statement: "During the next year, there is a 1-in-10 chance that the S\&P 500 return will be higher than _ \%" as well as the analogous question for the "lower" equity return. This allows us to examine each respondent's distribution of expected returns. We can recover a measure of volatility as well as skewness from each individual's responses.

While the survey is anonymous, we ask questions about the firms' characteristics. Fig. 1 presents summary information about the firms in our sample. For this figure, we do not include the characteristics of the firms that participated in the North Carolina CFO Symposium - but concentrate on the quarterly survey participants. We examine three characteristics: industry, revenue, and number of employees.

\section{The market risk premium and volatility}

\subsection{Risk premium}

Fig. 2 and 3 present histograms of the ex ante one-year and 10-year risk premia. In Fig. 2, the average one-year risk premium ranges from $0.1 \%$ (September 10, 2001 survey) to $3.0 \%$ (December 4, 2000). Each of the graphs contains the previous week and previous month's S\&P 500 return. Note that the market return was negative preceding the September 10, 2001 survey, and that the average risk premium is the lowest for this survey, $0.1 \%$. Also, for this survey we only include observations that faxed before September 11, 2001.

In Fig. 3, the 10-year risk premium is much more stable ranging from $3.6 \%$ (September 10, 2001) to $4.7 \%$ (September 7, 2000). Even after the large negative returns in the first quarter of 2001, the survey for the March 12, 2001 shows a $4.5 \%$ risk premium.

\footnotetext{
${ }^{1}$ Later in our analysis, using the non-CFO Symposium data, we test whether headquarters location explains variation in the risk premium across respondents. We find no evidence of a headquarters effect which provides another justification for integrating the CFO Symposium into our results.
} 
Fig. 4 examines whether the past quarter's market performance affects the average one-year and ten-year risk premium. ${ }^{2}$ In panel A of Fig. 4, there is a significant relation between the average risk premium and the previous quarter's return. Note that the data for the North Carolina CFO survey is presented with a different symbol, a circle. The results of this survey do not appear unusual. Panel $\mathrm{B}$ shows that there is no obvious relation between recent quarterly returns and the 10-year risk premium. While CFOs' assessments of the one-year risk premium appear strongly influenced by recent returns, there is no impact on the 10-year premium. $^{3}$

Table 1 presents regressions that use all of the data (rather than the means of the surveys which are presented in Fig. 4). We estimate weighted least squares regressions where the weights are the inverse of each quarter's variance. Consistent with the graphical analysis, recent realized returns significantly impact the respondents' forecasts of the one-year premium. ${ }^{4}$ There is an insignificant relation between the previous return and the 10-year premium. Our one-year results might be capturing an expectational momentum effect. Momentum occurs when future returns are related to past returns. We find that expected future returns are related to past returns.

\subsection{Volatility and disagreement}

We use Davidson and Cooper's (1976) method to recover the probability distribution:

$$
\text { Variance }=([x(0.90)-x(0.10)] / 2.65)^{2}
$$

\footnotetext{
${ }^{2}$ We also examined the past month. The results are broadly similar and are available on request.

${ }^{3}$ Given that we know the day that the survey was returned, we also investigate whether the past day's return affects the forecasted risk premium. We find evidence that the past day's return has an impact on the one-year forecast and little impact on the 10-year forecast. These results are available on request.
} 
where $x(0.90)$ and $x(0.10)$ represent the $90^{\text {th }}$ and $10^{\text {th }}$ percentile of the respondent's distribution. Keefer and Bodily (1983) show that this simple approximation is the preferred method of estimating the variance of a probability distribution of random variables, given information about the $10^{\text {th }}$ and $90^{\text {th }}$ percentiles. Note that this method allows us to estimate the market variance for each individual survey response.

The distribution of the individual volatilities is presented in Fig. 5. In all cases, the mean volatility is less than seven percent on an annual basis. This is sharply lower than other benchmark measures of volatility, such as the implied volatility on S\&P100 index options (VIX). During this time period, the VIX trades between 21 and $35 \%$. However, the VIX roughly measures the standard deviation of daily returns over the next month whereas we are looking for a longer-term volatility. But even if we examine the historical standard deviation of one-year returns (13.0\% 1980-2000; 20.1\% 1926-2000), the difference between this benchmark and the individual responses suggests that there is a large gap between the individual and market's assessments of volatility. Because the CFO's distributions are very tight, another interpretation is that the CFOs are very confident in their risk premium assessments.

While many studies have econometrically documented a relation between the past returns and volatility, to the best of our knowledge is the first research to examine the relation in the context of survey evidence. Panel A of Fig. 6 shows a somewhat negative relation between the average of the individual ex ante volatilities and the previous quarter's return. However, the regression evidence in

\footnotetext{
${ }^{4}$ This is also consistent with Welch (2001) who shows in a survey of economists that the mean one-year premium in 1998 was 5.8\% (near the peak of the stock market) and only $3.4 \%$ in 2001 (after a sizable retreat in the market).
} 
Table 2 that uses all the observations ${ }^{5}$ is much weaker. The slope coefficient is not significantly different from zero.

Importantly, market volatility is not the average of individual volatilities. To see this, consider the extreme situation in which everybody has highly confident forecasts (low individual volatility) but considerable disagreement exists across individuals (high cross-sectional dispersion in the risk premium forecasts). ${ }^{6}$

Panel B of Fig. 6 explores this second component of market volatility -- the notion of disagreement. The evidence suggests a sharp negative relation between disagreement and recent returns. That is, large negative returns are associated with a lot of disagreement. The effect is robust to using the previous month instead of the previous quarter's return (unreported).

The final panel in Fig. 6 examines disagreement over the 10-year risk premium and past returns. With this longer horizon forecast, there is not a strong relation between disagreement and past returns.

\subsection{Asymmetry in distributions}

The survey also captures information on skewness in the individual distributions, which we call asymmetry. We employ a simple metric of asymmetry. We look at the difference between each individual's $90 \%$ tail and the mean forecast and the mean minus the 10\% tail. Hence, if the respondent's forecast of the risk premium is $6 \%$ and the tails are $-8 \%$ and $+11 \%$, then the distribution is negatively skewed with a value of $-9 \%$.

Fig. 7 presents histograms of this asymmetry measure for the quarterly surveys. There is substantial asymmetry in the expectations of the risk premium. Indeed,

${ }^{5}$ There are fewer observations in Tables 2 and 3 than Table 1 because a number of respondents did not fill in the range questions. 
asymmetric distributions are the rule not the exception. The average asymmetry is generally positive (e.g., panels A, B, C and D). The ex ante asymmetry is quite negative in both the March 12, 2001 and the September 10, 2001 surveys. These are the quarters where the previous three months' stock market returns are very negative.

Fig. 7 suggests a relation between recent return performance and expected asymmetry in the returns distribution. Fig. 8 combines the information from all the surveys and finds a strong positive relation between recent returns and asymmetry. Large negative returns are associated with negative asymmetry in the respondents' distribution of the ex ante risk premium.

Table 3 confirms the highly significant positive relation. Both the lagged onemonth and one-quarter returns significantly positively influence the measure of asymmetry. All the coefficients are more than four standard errors from zero.

\subsection{The relation between expected returns and volatility}

Our results offer some new insights on the modeling of volatility. We have already demonstrated that low or negative realized returns are associated with higher expected volatility and more negative asymmetry in the ex ante returns distributions. This is consistent with the statistical evidence of asymmetry in GARCH modeling (e.g., Nelson (1992) and Glosten, Jagannathan and Runkle (1994)). The statistical evidence usually relies on the leverage hypothesis of Black (1976) and Christie (1982). We refer to this work as statistical evidence because the volatility is measured statistically from past returns data. ${ }^{7}$ We offer corroboration by linking past returns to a survey-based ex ante measure of volatility.

\footnotetext{
${ }^{6}$ The variance of returns is the sum of the average of the forecasters' variances and the variance of the forecasters' means. In terms of conditional expectations, $\operatorname{Var}[\mathrm{r}]=\mathrm{E}[\operatorname{Var}(\mathrm{r} \mid \mathrm{Z})]+\operatorname{Var}(\mathrm{E}[\mathrm{r} \mid \mathrm{Z})]$, where $\mathrm{r}$ represents returns and $\mathrm{Z}$ is the conditioning information that forecasters use.
} 
Given that we have new measures of expected (rather than realized) returns and the ex ante volatility, we can say something about the link between expected returns to expected risk - a fundamental component of asset pricing theory. Indeed, there is a considerable research on this topic which exclusively relies on statistical measures of both the mean and volatility based on historical data. However, the literature is evenly split on whether there is a positive relation or a negative relation between the mean and volatility.

For example, using a GARCH framework, French, Schwert and Stambaugh (1987) and Campbell and Hentshel (1992) estimate a positive relation while Campbell (1987), Breen, Glosten, and Jagannathan (1989), Nelson (1991) and Glosten, Jagannathan and Runkle (1993) find a negative relation between the realized mean and volatility. Harrison and Zhang (1999) use a seminonparametric method and find a positive relation. Brandt and Kang (2001) use a latent VAR technique and document a strong negative correlation. Harvey (2001) uses a combination of nonparametric density estimation and GARCH models and finds that the relation depends on the instrumental variables chosen. Both Harvey (2001) and Brandt and Kang (2001) document a distinct counter-cyclical variation in the ratio of mean to volatility.

While our sample is limited in size, we are able to document the relation between a survey-based ex-ante mean and volatility over our surveys. Fig. 9 presents the evidence for three different measures of volatility: the average the respondents' volatilities, disagreement (standard deviation of risk premium forecasts) and a combined measure. The combined measure considers the variation in the location of the individual distributions in addition to considering

\footnotetext{
${ }^{7}$ Figlewski and Wang (2001) re-examine the leverage effect using options implied volatility as an alternative to volatility estimated from past returns.
} 
the volatility of each distribution (aggregate volatility is the mean of the variances plus the variance of the means). ${ }^{8}$

There is a mildly negative relation between the one-year mean and the average volatility in panel A of Fig. 9. In comparison, there is a sharp negative relation between the one-year mean and disagreement in panel B. While R-squares with so few data points can be misleading, the fit here is extraordinary, 93\%. The combined measure of volatility also shows a very strong negative relation (panel $\mathrm{C}$ in Fig. 9).

Almost all of the past research focuses on short-horizon forecasts of the risk premium and volatility. Our results link well to this past research. However, we also offer some insights on longer-term forecasts. While we only have a measure of disagreement for the one-year forecasts (we do not ask respondents about the $10^{\text {th }}$ and $90^{\text {th }}$ percentiles of the 10 -year distribution and, therefore, cannot deduce 10 -year volatility), our evidence suggests a strongly significant positive relation between the mean and volatility (panel D). That is, the ex ante relation between mean and volatility appears to be sensitive to the time horizon.

It is possible that the difference between the short-horizon and long-horizon provides some resolution to the conflicting findings in the literature. It seems reasonable that short-horizon expected returns could move around substantially producing either a positive or negative expected returns. Longer horizon returns, on the other hand, are more stable, as we document.

Pástor and Stambaugh have recently presented a Bayesian analysis of longhorizon risk premia. They find that the risk premium in the 1990s is $4.8 \%$ which is consistent with our results. However, a critical component of their analysis is the tying of their prior to a positive relation between the premium and volatility. If Pástor and Stambaugh instead chose a diffuse prior relation between volatility and

\footnotetext{
${ }^{8}$ We appreciate the insights of Bob Winkler on this particular point.
} 
the premium, their estimate of the risk premium in June 1999 rises dramatically to $27.7 \%$. The lower risk premium in the 1990s in the face of high ex post average returns is a result of lower volatility in the market. ${ }^{9}$ Our results support the prior they impose.

As a robustness check, we obtain data from the Federal Reserve Board of Philadelphia's Survey of Professional Forecasters. Once a year, the quarterly survey asks a question about the respondent's expected 10-year return on the S\&P 500 index. The analysis of this relation is contained in panel $\mathrm{E}$ of Fig. 9. We present the risk premium and disagreement for ten surveys beginning in 1992.

Consistent with panel $\mathrm{D}$, there is a positive relation between the expected premium and the expected volatility using these alternative data. There are also differences. There is a much greater variation in disagreement and the risk premium tends to be smaller in the Fed survey. However, these surveys were obtained over a 10-year period where as panel D represents a shorter sample. Nevertheless, the positive relation using long-horizon returns appears to be robust to at least one additional survey.

\subsection{Do firm characteristics impact expectations?}

Our survey collects information on six firm characteristics: industry, revenue, number of employees, headquarters location, ownership and percentage of sales from foreign sources. It is possible that expectations of market-wide measures like the risk premium might depend on firm characteristics. For example, we have established that the one-year premium depends on past market returns. Is the premium significantly different across the respondents' industries? Given that a

\footnotetext{
${ }^{9}$ Pastor and Stambaugh show the volatility is $12.8 \%$ in the 1990 s compared to $17.0 \%$ in their full sample.
} 
market-wide measure is being forecasted, our null hypothesis is that there are no significant differences across firm characteristics.

In unreported results, we estimate six regression models (one for each of the characteristics). We regress the risk premium on a series of indicator variables representing fixed effects for each firm characteristic. We also include an indicator variable for each survey date. In all six regressions, the coefficients on the characteristic indicators are not significant at the usual levels of confidence. As a result, we do not reject the null hypothesis that firms' characteristics have no impact on market-wide expectations.

\subsection{The September 11, 2001 crisis}

Our survey was faxed to CFOs at 8:00am on September 10, 2001. The results in the tables and figures only include data through September 10. However, we have responses that were returned after the crisis. Although the post-crisis sample is small, it is interesting to examine the impact of what we consider a shock to systematic risk because terrorism is undiversifiable in world markets.

Table 4 presents summary statistics for both the September 10 and the postSeptember 11 sample. We exclude September 11 because some of the surveys we received may have been completed the day before.

The first panel examines the one-year premium which decreases from $0.05 \%$ to $-0.70 \%$ even though both measures of volatility increase substantially. The second panel shows a sharp increase in the 10-year premium from $3.63 \%$ to $4.82 \%$. Consistent with the one-year analysis, the volatility increases. While these differences are economically interesting, they are not significantly different because of the small number of observations in the post-September 11 sample.

The differences between the one-year premium and the 10 -year premium are consistent with our other analysis. The responses to the one-year premium are likely what the CFOs think will happen near-term in the market - not necessarily 
what they would require to make a capital investment. However, the 10-year premium more likely represents both expected returns and required returns. In this case, what appears to be a shock to systematic risk, has led to perceptions of higher required returns in equity markets.

\section{Conclusions}

While surveys of the risk premium are not new, we provide a number of new insights. First, we survey Chief Financial Officers of U.S. corporations and argue that they are uniquely well suited to assess the risk premium given that they routinely use this input in their capital allocation decisions. In addition, we are not particularly concerned that the CFOs are biased in their assessment of the premium - a concern that we have for surveys of financial analysts.

Our survey is designed to look at different horizons (one-year versus 10-year) and, most importantly, to recover the distribution of the risk premium through time. Our survey evidence finds that the one-year premium varies between 0.1 and $2.5 \%$ and the 10 -year premium falls in the 3.6 to $4.7 \%$ range. We find that recent past stock market performance has a large effect on the expected one-year premium and only a small effect on the 10-year premium.

We find that past returns significantly impact volatility as well as the degree of asymmetry in the respondents' distributions. Indeed, we find convincing evidence that recent low returns are associated with higher volatility and more negative asymmetry (i.e., relatively large left tails in the distributions of the expected risk premium). Our evidence supports the statistical evidence that negative return shocks increase volatility.

We have also attempted to shed some light on the relation between the mean and volatility. All previous research has relied on historic data to statistically measure the mean and the variance and this research is split on whether there is a positive relation or negative relation between reward and risk. Our evidence 
suggests that at the one-year horizon there is a negative relation between the mean and the variance. This poses a challenge to asset pricing theory which implies a positive tradeoff between risk and expected returns. However, at the 10-year horizon, there is evidence of a significantly positive relation. As a robustness experiment, we examine the relation between the ten-year risk premium and dispersion from a Federal Reserve Bank of Philadelphia survey from 1992-2001 and confirm the positive relation between mean and volatility.

Finally, let us emphasize that our work is ongoing. While we have over 1,100 survey responses, much of the analysis presented relies on seven aggregated observations. Indeed, this is the reason that we have mainly presented the data graphically. By viewing these data, each reader can judge the influence of particular observations. Our goal is to continue the survey and dynamically augment this research as new results arrive.

\section{References}

Asness, C. S., 2000, Stocks vs. bonds: Explaining the equity risk premium, Financial Analysts Journa,l May/June.

Black, F. and R. Litterman, 1990, Asset allocation: Combining investors' views on market equilibrium, Goldman Sachs Fixed Income Research, September.

Black, F. and R. Litterman, 1991, Global asset allocation with equities, bonds and currencies, Goldman Sachs Fixed Income Research, October.

Brandt, M. W. And Q. Kang, 2001, On the relation between the conditional mean and volatility of stock returns: A latent VAR approach, Unpublished working paper, University of Pennsylvania, Philadelphia, PA.

Brav, A., and R. Lehavy, 2001, An empirical analysis of analysts' target prices: Short-term informativeness and long term dynamics, Unpublished working paper, Duke University.

Breen, W., L. R. Glosten and R. Jagannathan, 1989, Economic significance of predictable variation in stock index returns, Journal of Finance 44, 1177-1189.

Campbell, J. Y. and L. Hentschel, 1992, No news is good news: An asymmetric model of changing volatility in stock returns, Journal of Financial Economics 31, 281-318.

Campbell, J. Y., 1987, Stock returns and the term structure, Journal of Financial Economics 18, 373-400.

Chen, N.-f., R. Roll, and S. A. Ross, 1986. Economic forces and the stock market. Journal of Business 59, 383-404. 
Claus, J. and J. Thomas, 2001, Equity premia as low as three percent: Evidence from analysts' earnings forecasts for domestic and international stock markets, Journal of Finance 56, 16291666.

Christie, A. A., 1982, The stochastic behavior of common stock variances: Value, leverage, and interest rate effects, Journal of Financial Economics 10, 407-432.

Davidson, L. B., and D. O. Cooper, 1976, A simple way of developing a probability distribution of present value, Journal of Petroleum Technology, September, 1069-1078.

Fama, E. F. and French, K. R., 1992. The cross-section of expected stock returns. Journal of Finance 47, 427-465.

Fama, E. F. and French, K. R., 2001, The equity premium, Unpublished working paper, University of Chicago, Chicago, IL.

Ferson, W. E. and Harvey, C. R., 1991. The variation of economic risk premiums. Journal of Political Economy 99, 285-315.

Ferson, W. E. and Harvey, C. R., 1993. The risk and predictability of international equity returns. Review of Financial Studies 6, 527-566.

Figlewski, S. and X. Wang, 2001, Is the 'leverage effect' a leverage effect?, Unpublished working paper, New York University, New York, NY.

French, K. R. and J. Poterba, 1991, Investor diversification and international equity markets, American Economic Review 81, 222-226.

French, K. R., G. W. Schwert and R. F. Stambaugh, 1987, Expected stock returns and volatility, Journal of Financial Economics 19, 3-30.

Fraser, P., 2001, How do U.S. and Japanese investors process information and how do they form their expectations of the future? Evidence from quantitative survey based data, Unpublished working paper, University of Aberdeen.

Gebhardt, W. R., C. M. C. Lee, and B. Swaminathan, 2000, Toward an implied cost of capital, Unpublished working paper, Cornell University, Ithaca, NY.

Giordani, P., and P. Soderlind, 2000, Inflation forecast uncertainty, Unpublished working paper, Stockholm School of Economics, Sweden.

Glosten, L. R., R. Jagannathan and D. Runkle, 1993, On the relation between the expected value and the volatility of the nominal excess returns on stocks, Journal of Finance 48, 1779-1802.

Goyal, A. and I. Welch, 1999, Predicting the risk premium, Unpublished working paper, University of California at Los Angeles, Los Angeles, CA.

Graham, J. R., 1999b. Quarter 2, 1999 FEI Survey. http://www.duke.edu/ jgraham.

Graham, J. R. and C. R. Harvey, 1996, Market timing ability and volatility implied in investment newsletters' asset allocation recommendations, Journal of Financial Economics, 397-422.

Graham, J. R. and C. R. Harvey, 2001, Theory and practice of corporate finance: Evidence from the field, Journal of Financial Economics, 60, 187-243.

Harris, R. S. and F. C. Marston, The market risk premium: Expectational estimates using analysts' forecasts, Unpublished working paper, University of Virginia, Charlottesville, VA

Harrison, P. and H. Zhang, 1999, An investigation of the risk and return relation at long horizon, Review of Economics and Statistics 81, 399-408.

Harvey, C. R., 2001, The specification of conditional expectations, Journal of Empirical Finance, forthcoming.

Heaton, J. and D. Lucas, 2000, Stock prices and fundamentals, in Ben S. Bernanke and Julio Rotemberg, Eds., NBER Macroeconomics Annual 1999, The MIT Press. 
Heaton, J. B., 2000, Managerial optimism and corporate finance. Unpublished working paper, University of Chicago.

Ibbotson, R. G. and P. Chen, 2001, The supply of stock returns, Unpublished working paper, Yale University.

Ibbotson Associates, 1998 Stocks, bonds, bills and inflation, 1998 yearbook, Chicago, IL.

Jagannathan, R. and Meier, I., 2001, Do we need CAPM for capital budgeting? Unpublished working paper, Northwestern University, Evanston, IL.

Jagannathan, R. and Wang, Z., 1996. The conditional CAPM and the cross-section of expected returns. Journal of Finance, 51, 3-53.

Jagannathan, R., E. R. McGrattan and A. Scherbina, 2001, The declining U.S. equity premium, Quarterly Review, Federal Reserve Bank of Mineapolis.

Keefer, D. L. and S. E. Bodily, 1983, Three-point approximations for continuous random variables, Management Science 29, 5 595-609.

Lamont, O. Earnings and expected returns, Journal of Finance 53, 1563-1587.

Lintner, J., 1965, The valuation of risky assets and the selection of risk investments in stock portfolios and capital budgets, Review of Economics and Statistics 9, 1033-1059.

Nelson, D. B., 1991, Conditional heteroskedasticity in asset returns: A new approach, Econometrica 59, 347-370.

Pástor, L. And R. Stambaugh, 2001, The equity premium and structural breaks, Journal of Finance, 56, 1207-1239.

Poterba, J. M. and Summers, L. H., 1995, A CEO sruvey of U.S. companies' time horizons and hurdle rates, Sloan Management Review, Fall, 43-53.

Sharpe, W., 1964, Capital asset prices: A theory of market equilibrium under conditions of risk, Journal of Finance 19, 425-442.

Siegel, J. J., 1999, The shrinking equity premium, Journal of Portfolio Management, 10-17.

Welch, I., 2000, Views of financial economists on the equity premium and other issues, Journal of Business 73 (October): 501-37.

Welch, I., 2001, The equity premium consensus forecast revisited, Unpublished working paper, Cowles Foundation for Research in Economics, Yale University, New Haven, CT. 


\section{Exhibit 1}

Survey question regarding the risk premium

4. On June 7th, the annual yield on 10-yr treasury bonds was 5.3\%. Please complete the following:*

a) Best Guess: Over the next 10 years, I expect the S\&P 500 will average a $\%$ annual return

b) Best Guess: During the next year, I expect the $S \& P$ to return $\%$

c) High range: During the next year, there is a 1 -in-10 chance the $S \& P 500$ return will be higher than $\%$

d) Low range: During the next year, there is a 1-in-10 chance the S\&P 500 return will be lower than

*Drawn from the survey of June 7, 2001. The rate on the 10-year Treasury bond changes in each survey. 
Table 1

The impact of past returns on risk premium forecasts

A. Including CFO Symposium

\begin{tabular}{rrrrr}
\multicolumn{2}{c}{ One-year premium } & & \multicolumn{2}{c}{ 10-year premium } \\
\cline { 1 - 1 } \cline { 5 - 5 } $\begin{array}{c}\text { Previous } \\
\text { quarter's return }\end{array}$ & $\begin{array}{c}\text { Previous } \\
\text { month's return }\end{array}$ & & $\begin{array}{c}\text { Previous } \\
\text { quarter's return }\end{array}$ & $\begin{array}{c}\text { Previous } \\
\text { month's return }\end{array}$ \\
\hline 2.34 & 2.21 & & 4.27 & 4.22 \\
15.40 & 15.40 & & 41.23 & 47.98 \\
& & & & \\
0.089 & 0.144 & & 0.016 & 0.013 \\
3.87 & 3.59 & & 1.31 & 0.77 \\
& & & 0.001 & 0.000 \\
0.012 & 0.010 & & 1154 & 1154 \\
1147 & 1147 & &
\end{tabular}

B. Excluding CFO Symposium

\begin{tabular}{|c|c|c|c|}
\hline \multicolumn{2}{|c|}{ One-year premium } & \multicolumn{2}{|c|}{ 10-year premium } \\
\hline $\begin{array}{c}\text { Previous } \\
\text { quarter's return }\end{array}$ & $\begin{array}{c}\text { Previous } \\
\text { month's return }\end{array}$ & $\begin{array}{c}\text { Previous } \\
\text { quarter's return } \\
\end{array}$ & $\begin{array}{c}\text { Previous } \\
\text { month's return }\end{array}$ \\
\hline 2.23 & 2.09 & 4.26 & 4.20 \\
\hline 12.94 & 13.66 & 39.18 & 46.94 \\
\hline 0.074 & 0.013 & 0.014 & 0.012 \\
\hline 2.88 & 3.23 & 1.13 & 0.69 \\
\hline 0.007 & 0.008 & 0.000 & -0.001 \\
\hline 1109 & 1109 & 1116 & 1116 \\
\hline
\end{tabular}


Table 2

The impact of past returns on forecast volatility

\begin{tabular}{|c|c|c|c|c|}
\hline & \multicolumn{2}{|c|}{$\begin{array}{l}\text { A. Including CFO Symposium } \\
\text { One-year forecast volatility }\end{array}$} & \multicolumn{2}{|c|}{$\begin{array}{l}\text { B. Excluding CFO Symposium } \\
\text { One-year forecast volatility }\end{array}$} \\
\hline & $\begin{array}{c}\text { Previous } \\
\text { quarter's return } \\
\end{array}$ & $\begin{array}{c}\text { Previous } \\
\text { month's return }\end{array}$ & $\begin{array}{c}\text { Previous } \\
\text { quarter's return } \\
\end{array}$ & $\begin{array}{c}\text { Previous } \\
\text { month's return }\end{array}$ \\
\hline Intercept & 6.71 & 6.78 & 7.01 & 6.98 \\
\hline$T$ ratio & 41.54 & 45.18 & 39.90 & 44.86 \\
\hline Previous return & -0.029 & -0.016 & 0.008 & 0.003 \\
\hline T ratio & -1.33 & -0.47 & 0.33 & 0.07 \\
\hline Adj. $R^{2}$ & 0.001 & -0.001 & -0.001 & -0.001 \\
\hline Observations & 911 & 911 & 877 & 877 \\
\hline
\end{tabular}


Table 3

The impact of past returns on forecast asymmetry

\begin{tabular}{|c|c|c|c|c|}
\hline & \multicolumn{2}{|c|}{$\begin{array}{l}\text { A. Including CFO Symposium } \\
\text { One-year forecast asymmetry }\end{array}$} & \multicolumn{2}{|c|}{$\begin{array}{l}\text { B. Excluding CFO Symposium } \\
\text { One-year forecast asymmetry }\end{array}$} \\
\hline & $\begin{array}{c}\text { Previous } \\
\text { quarter's return }\end{array}$ & $\begin{array}{c}\text { Previous } \\
\text { month's return }\end{array}$ & $\begin{array}{c}\text { Previous } \\
\text { quarter's return } \\
\end{array}$ & $\begin{array}{c}\text { Previous } \\
\text { month's return }\end{array}$ \\
\hline Intercept & -0.86 & -0.94 & -0.88 & -1.11 \\
\hline T ratio & -3.27 & -3.69 & -2.80 & -3.93 \\
\hline Previous return & 0.154 & 0.234 & 0.153 & 0.219 \\
\hline T ratio & 4.88 & 4.90 & 4.22 & 4.46 \\
\hline Adj. $R^{2}$ & 0.025 & 0.025 & 0.019 & 0.021 \\
\hline Observations & 911 & 911 & 877 & 877 \\
\hline
\end{tabular}


Table 4

The impact of the September 11, 2001 crisis on expectations

One-year risk premium

Mean premium

Pre-September 11 Post-September 11*

Std. dev. (disagreement)

$0.05 \quad-0.70$

Std. dev. (average of individual volatilities)

$6.61 \quad 7.86$

Asymmetry (disagreement)

$6.79 \quad 9.76$

Asymmetry (average of individual asymmetries)

$\begin{array}{ll}-2.24 & 1.96\end{array}$

Observations

$\begin{array}{ll}-0.82 & -0.57\end{array}$

$125 \quad 33$

10-year risk premium

Mean premium

4.82

Std. dev. (disagreement)

2.36

3.03

Asymmetry (disagreement)

$-0.36$

0.14

Observations

127

33

*Surveys faxed on September 11 were excluded from both samples. 
The characteristics of the survey respondents' firms
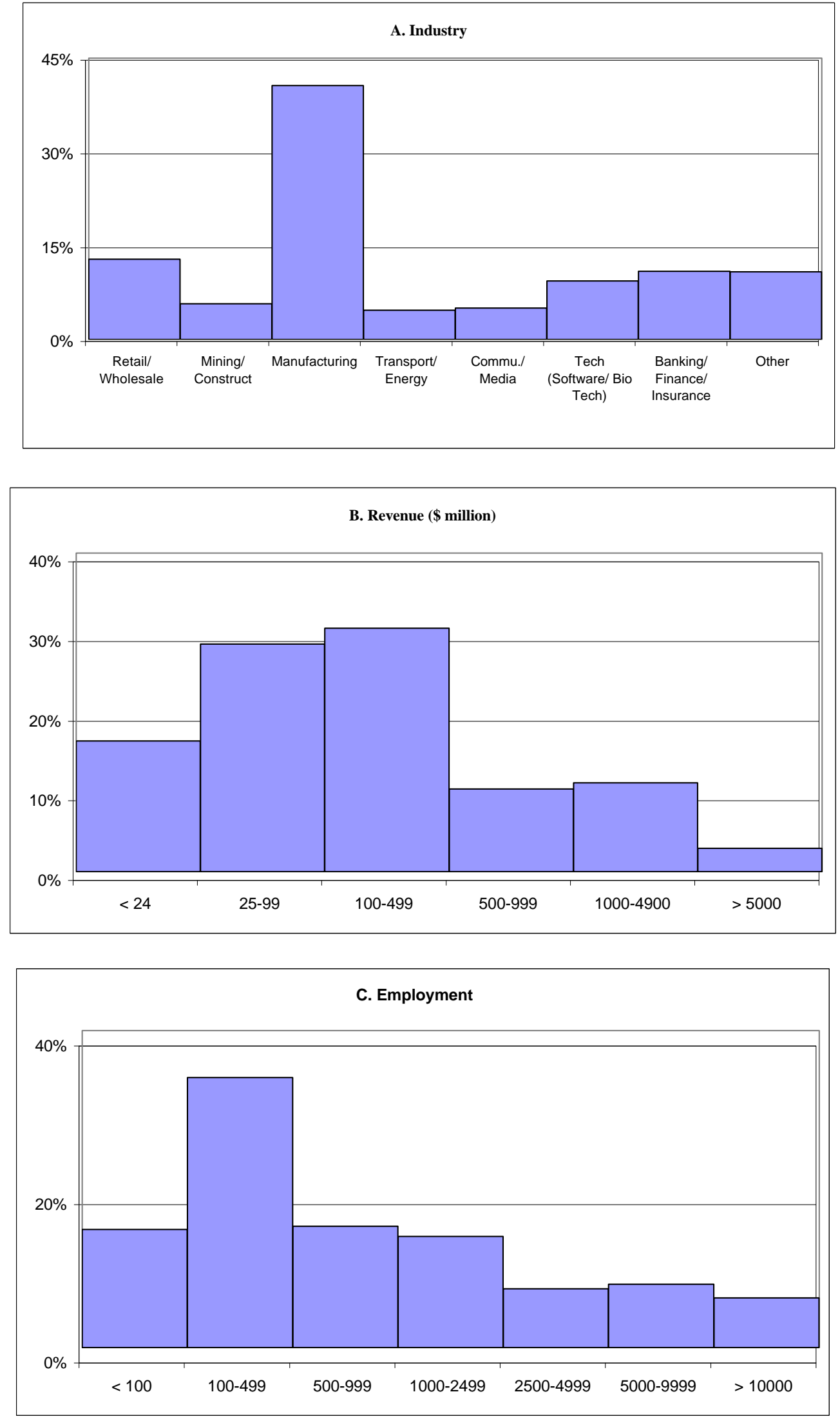

Fig. 1 
The distribution of the expected one-year risk premium

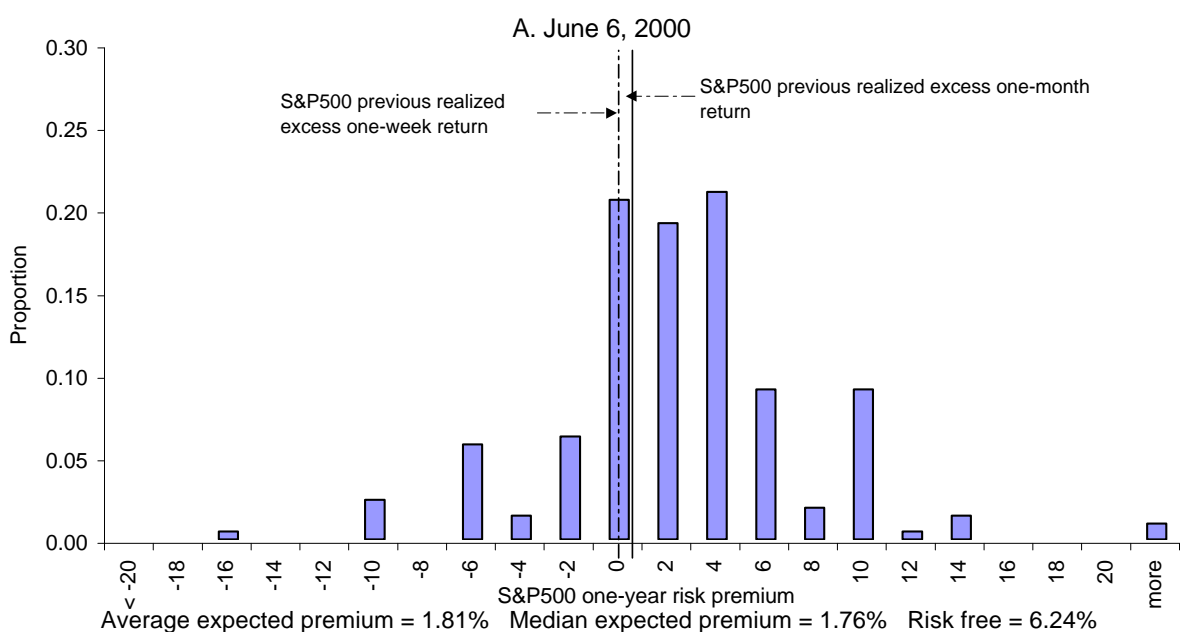

Average expected premium $=1.81 \%$ Median expected premium $=1.76 \%$ Risk free $=6.24 \%$ Std. dev. $=5.22 \%$ Skewness $=0.33 \%$ Responses $=209$

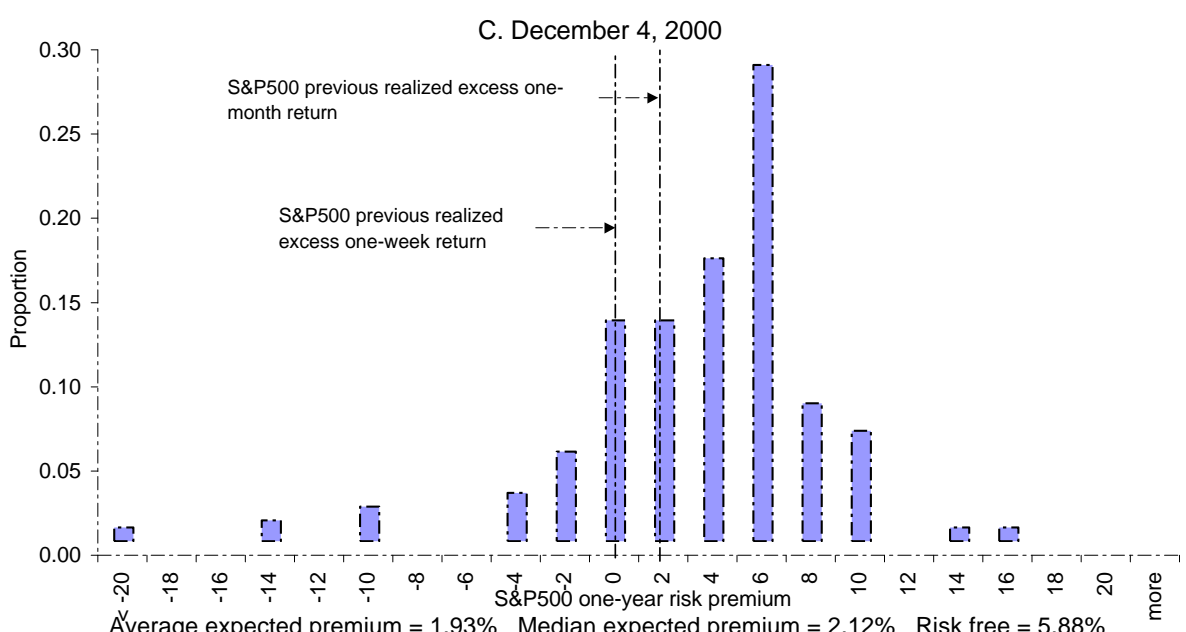

Std. dev. $=4.99 \%$ Skewness $=-1.44 \%$ Responses $=244$

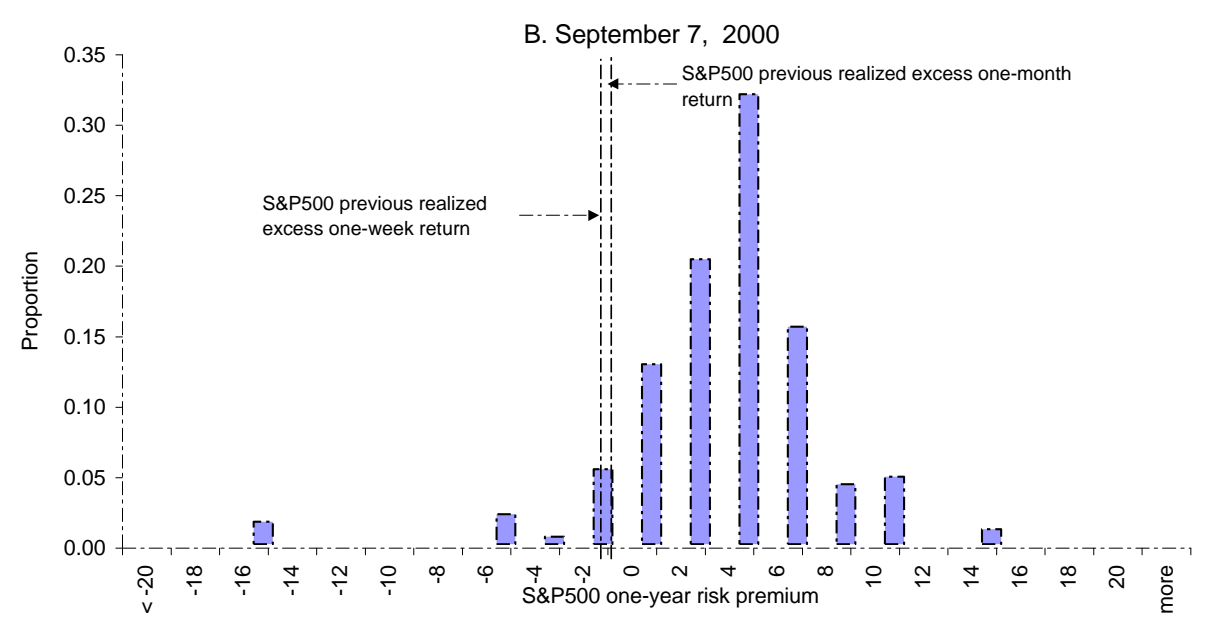

Average expected premium $=2.5 \%$ Median expected premium $=3.28 \%$ Risk free $=6.22 \%$ Std. dev. $=4.10 \%$ Skewness $=-1.42 \%$ Responses $=188$

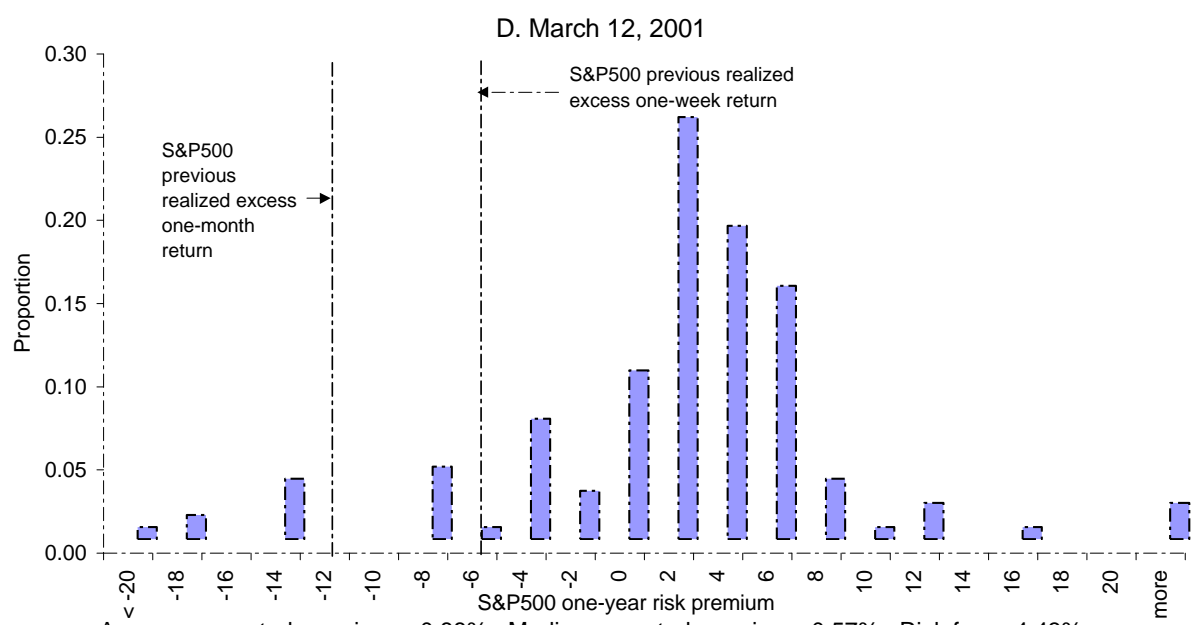

Average expected premium $=0.88 \%$ Median expected premium $=0.57 \%$ Risk free $=4.43 \%$

Std. dev. $=6.91 \%$ Skewness $=-0.36 \%$ Responses $=138$ 
The distribution of the expected one-year risk premium
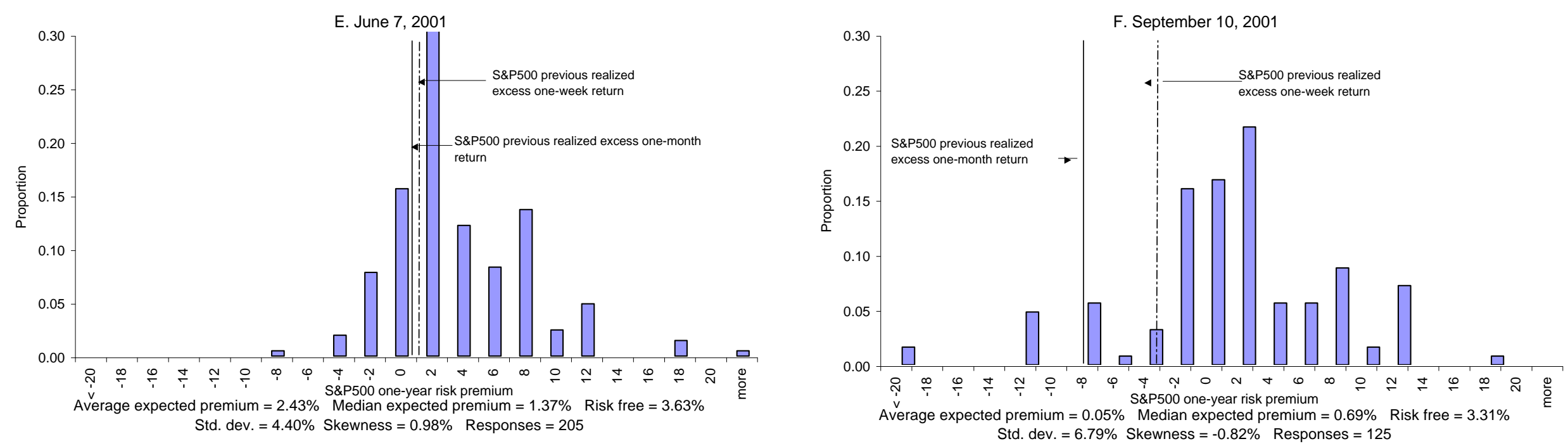

Fig. 2 (continued) 
The distribution of the expected 10-year risk premium
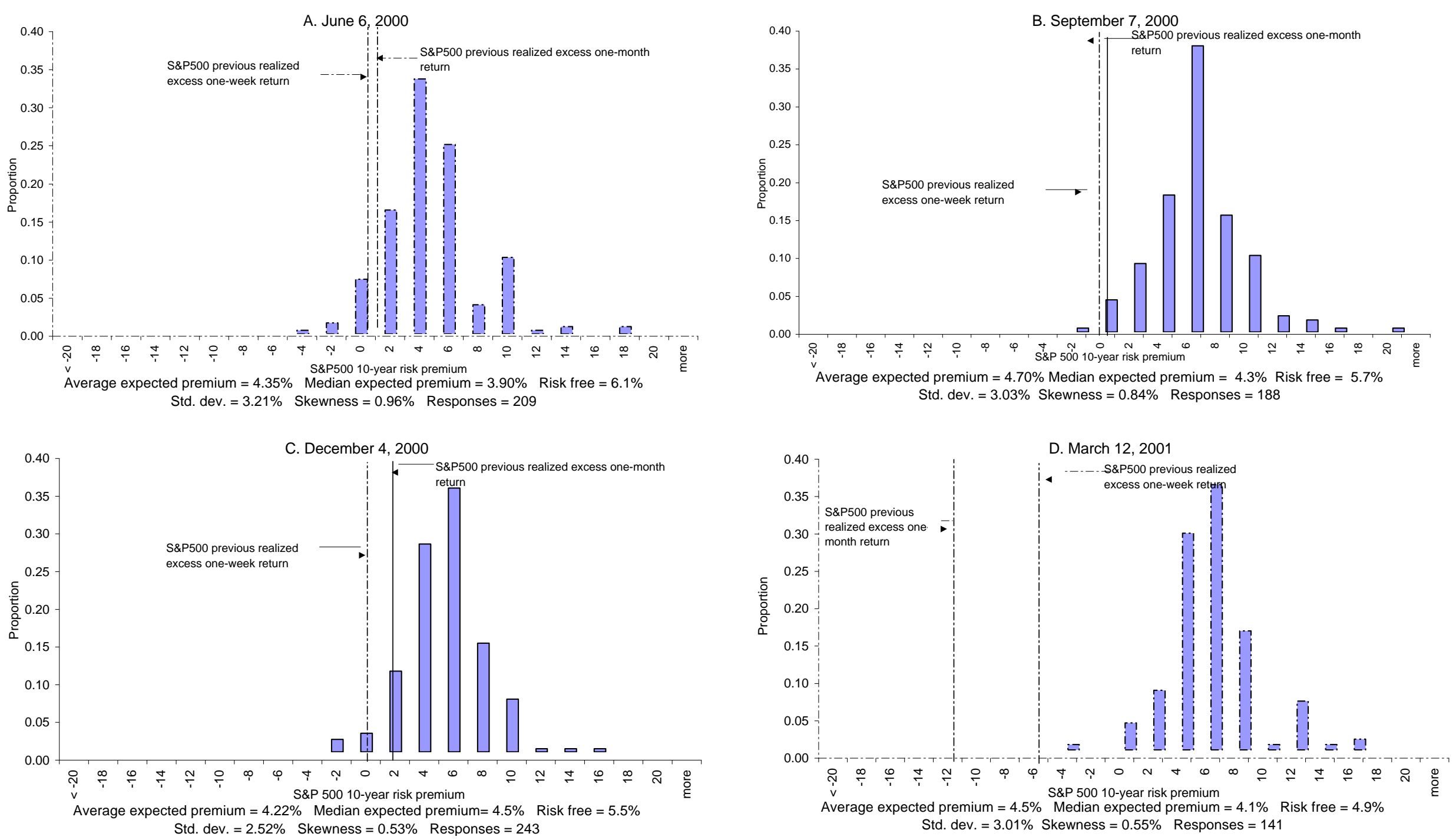
The distribution of the expected 10-year risk premium

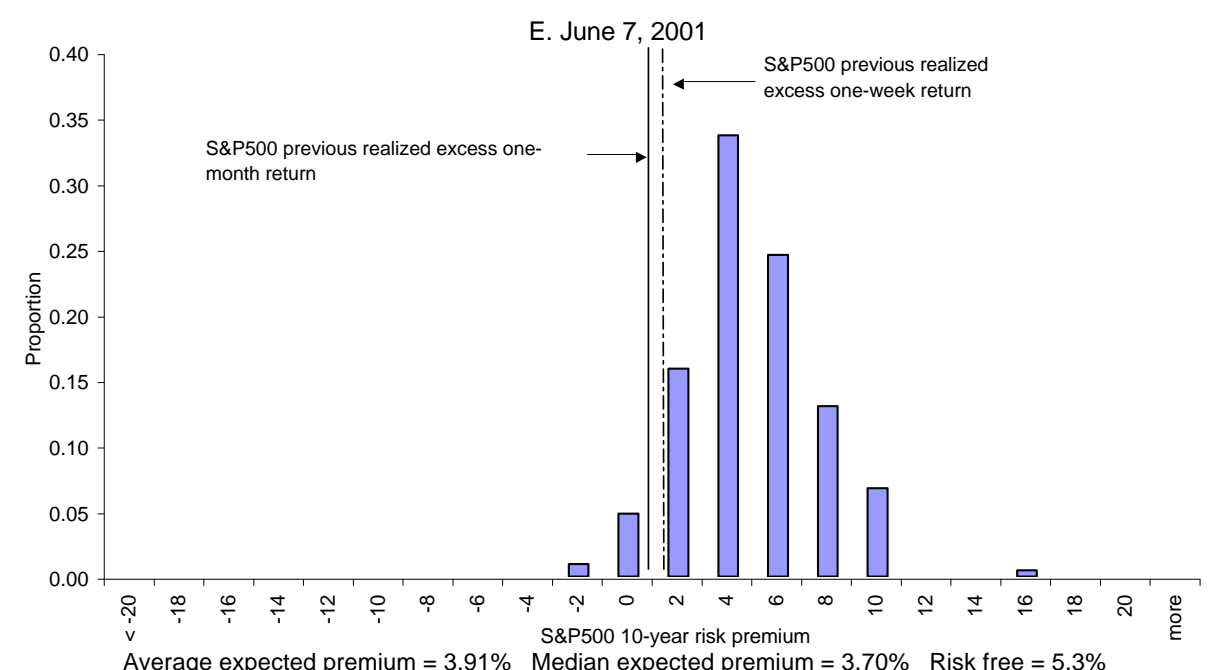

Std. dev. $=2.64 \%$ Skewness $=0.59 \%$ Responses $=208$

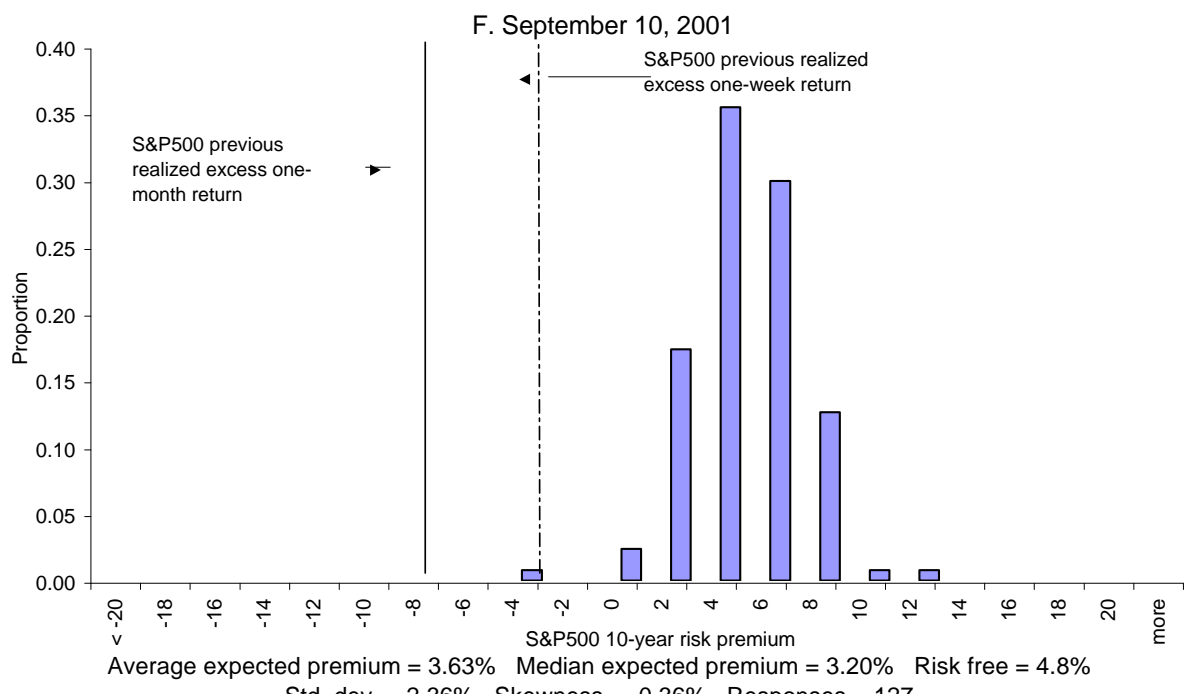

Std. dev. $=2.36 \%$ Skewness $=-0.36 \%$ Responses $=127$

Fig. 3 (continued) 
Past returns and the one year ex-ante risk premium

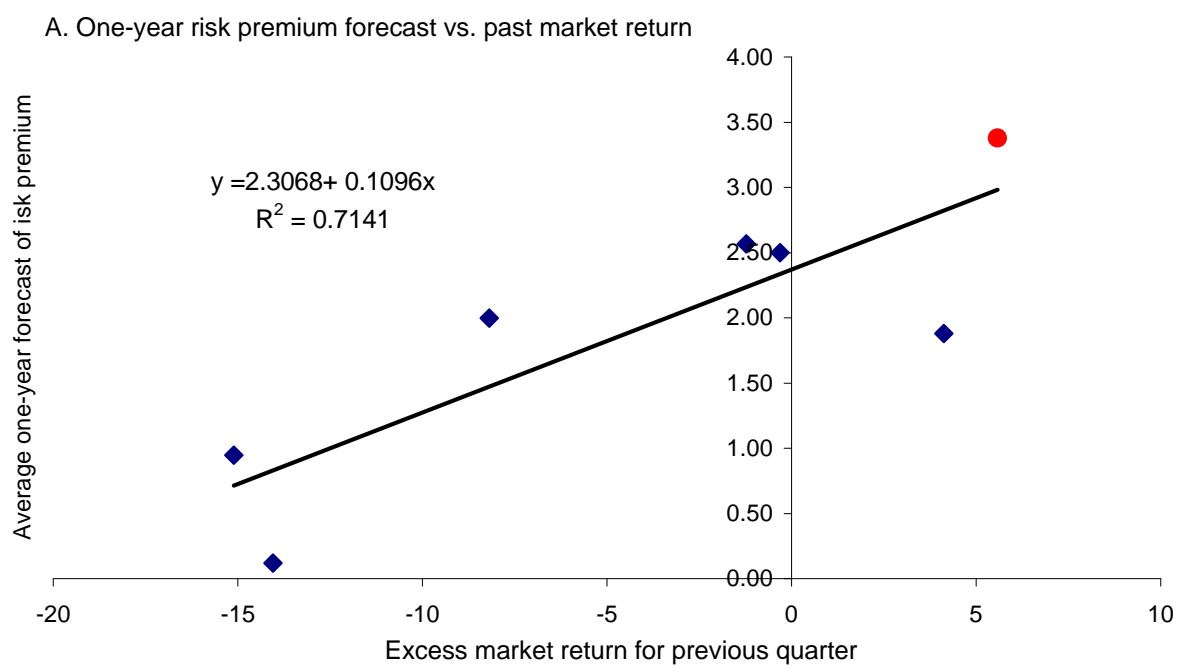

Fig. 4
B. Ten-year forecast vs. market return

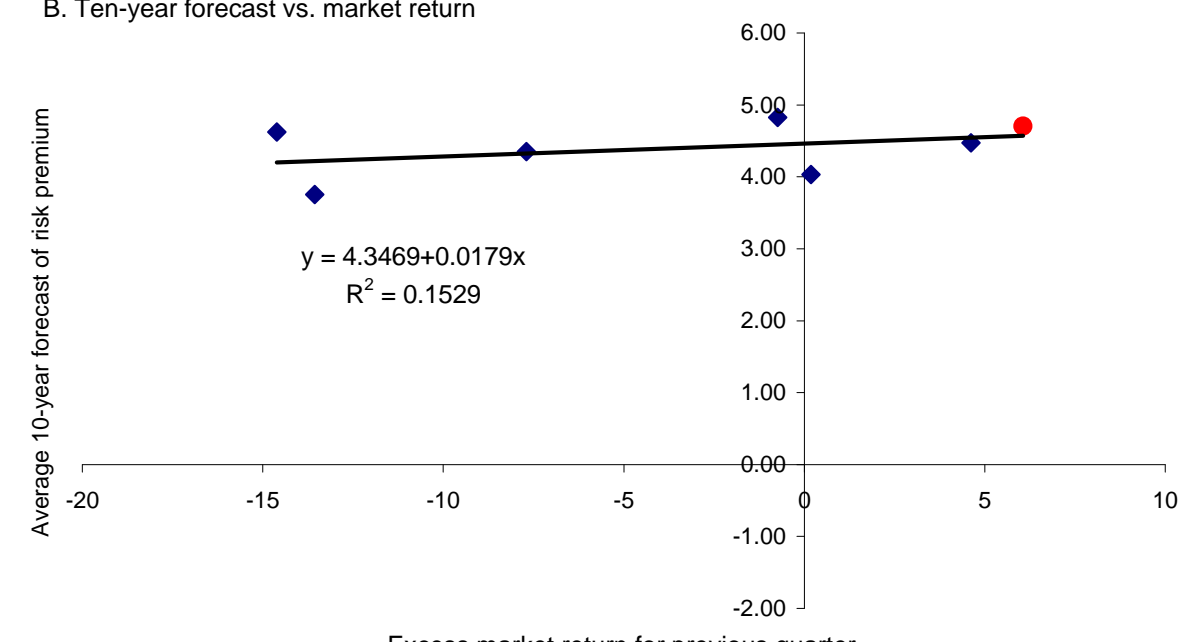

Excess market return for previous quarter 
The distribution of ex ante volatility for one-year return forecasts

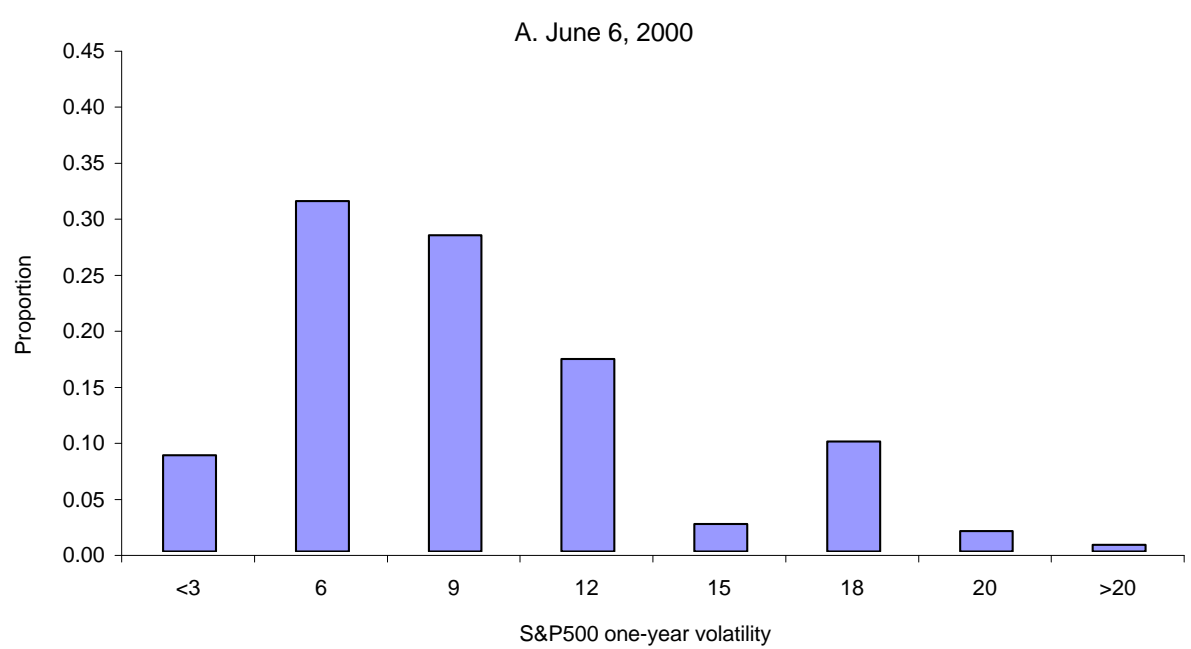

Average $=7.80 \%$ Median $=7.55 \%$ Std. dev. $=4.32 \%$ One month prior VIX $=30.39$

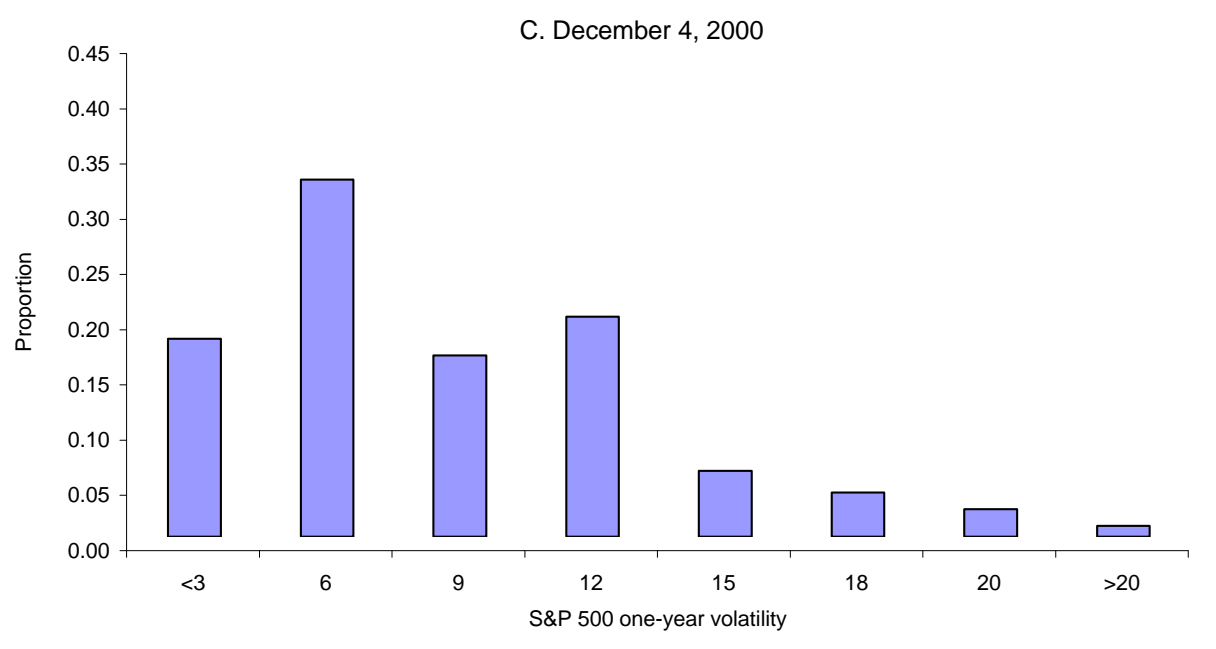

Average $=7.25 \%$ Median $=5.66 \%$ Std. dev. $=4.47 \%$ One month prior VIX $=32.50$

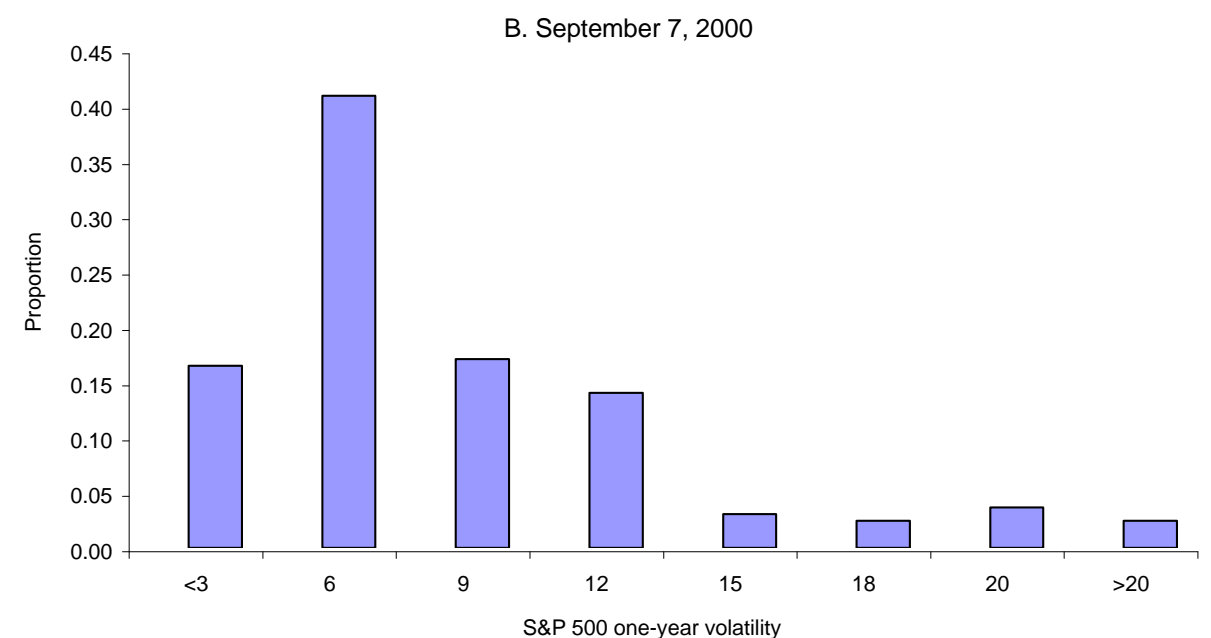

Average $=7.10 \%$ Median $=5.66 \%$ Std. dev. $=5.17 \%$ One month prior VIX $=21.55$

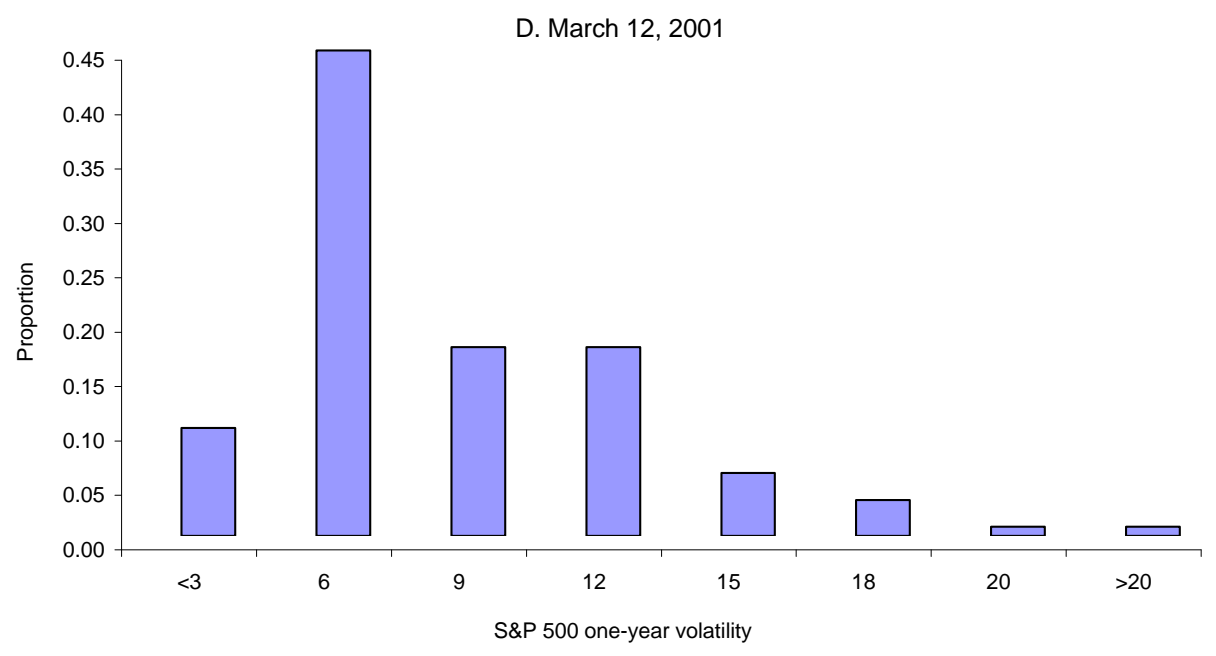

Average $=7.16 \%$ Median $=5.66 \%$ Std. dev. $=5.15 \%$ One month prior VIX $=35.11$ 
The distribution of ex ante volatility for one-year return forecasts

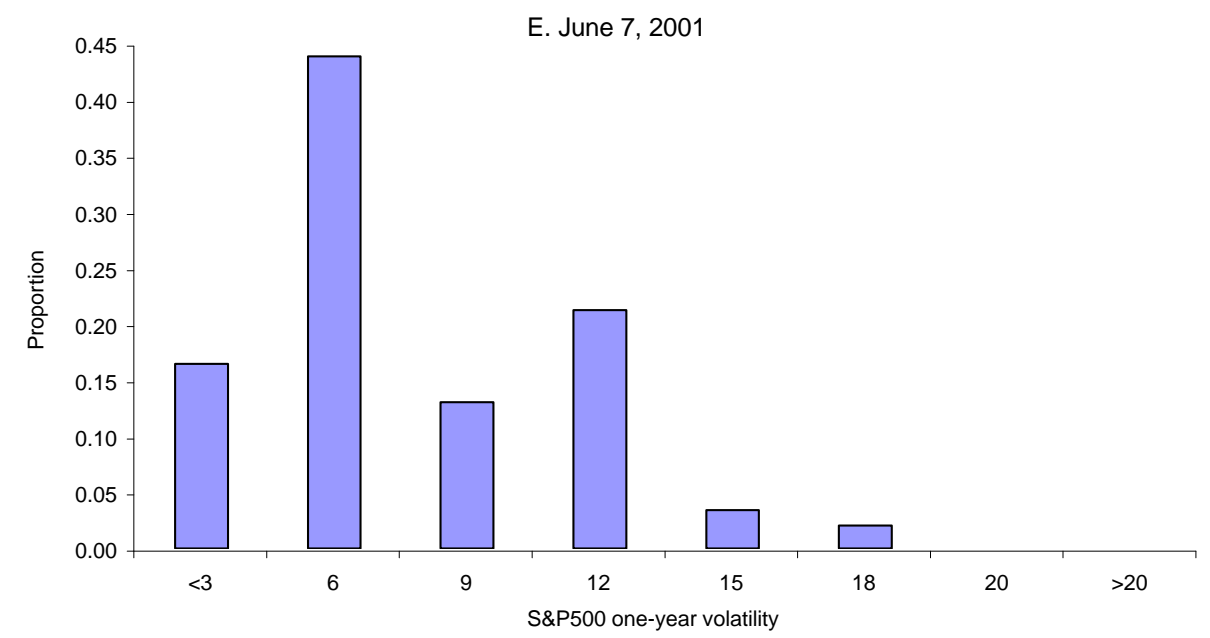

Average $=6.14 \%$ Median $=5.66 \%$ Std. dev. $=3.48 \%$ One month prior VIX $=27.54$

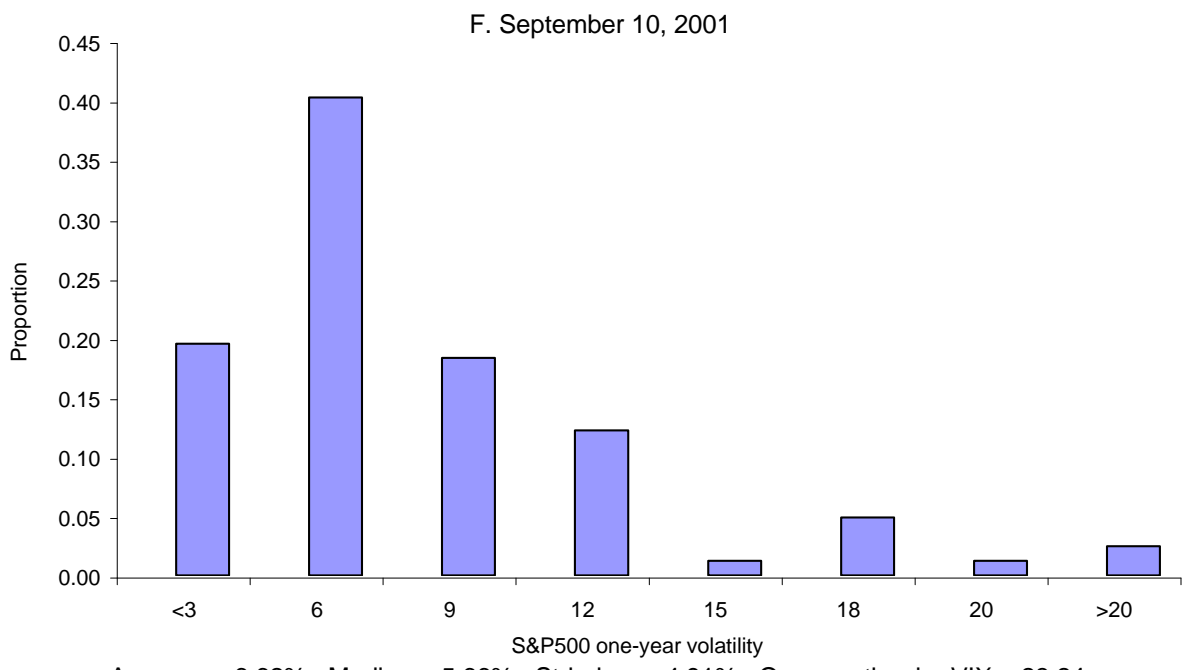

Average $=6.62 \%$ Median $=5.66 \%$ Std. dev. $=4.91 \%$ One month prior VIX $=23.24$

Fig. 5 (continued) 
Past returns and volatility

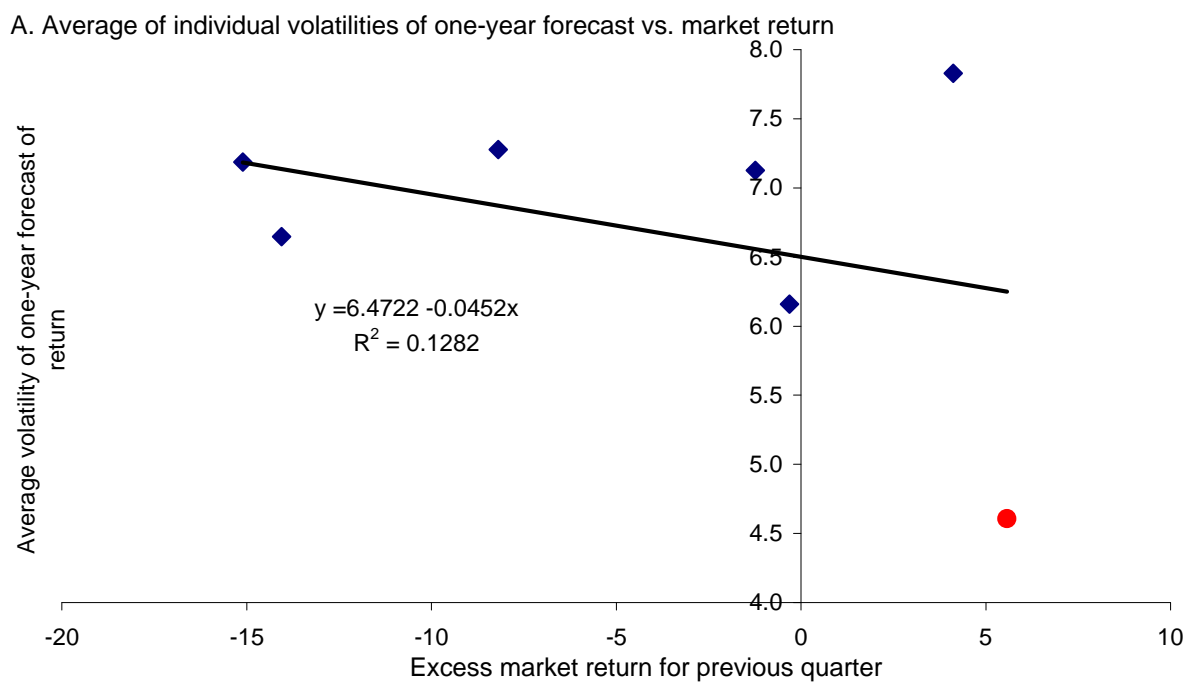

B. Disagreement (std. dev. of one-year forecasts) vs. market return

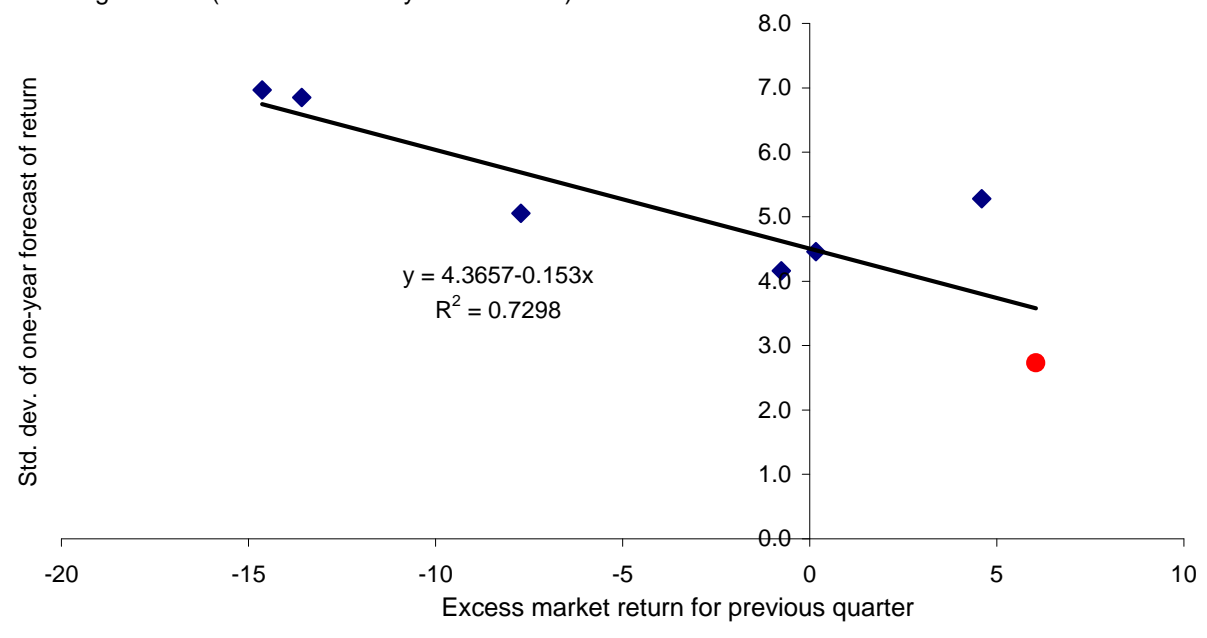

C. Disagreement (std. dev. of 10-year forecast) vs. market return

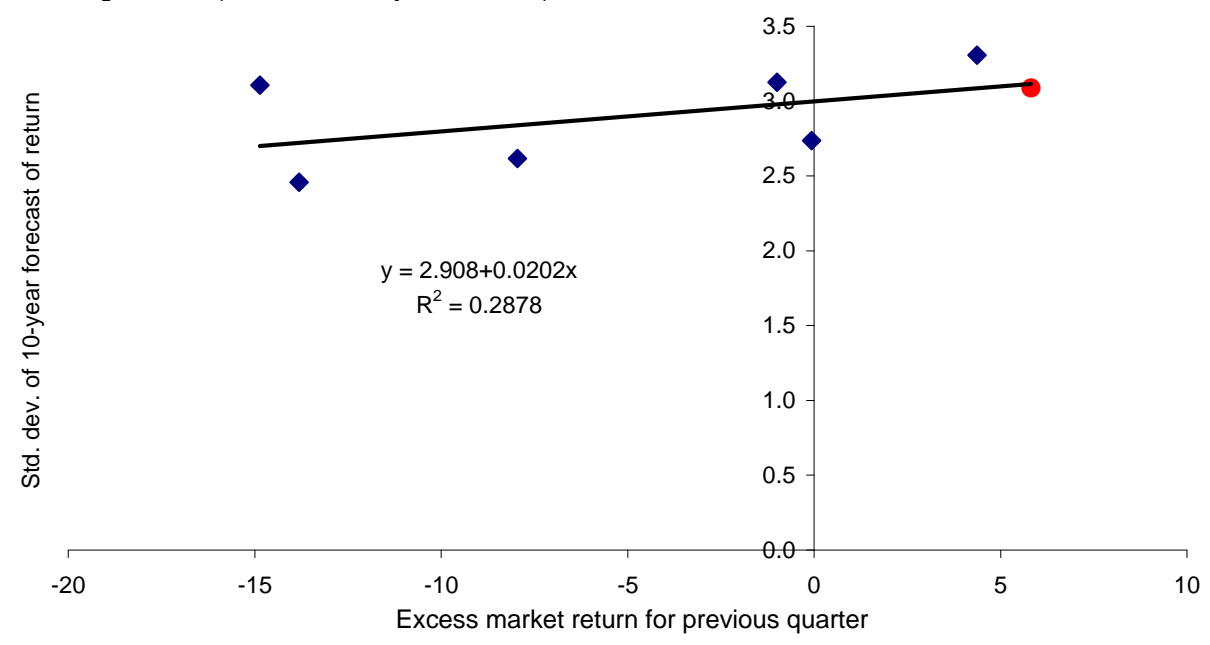

Fig. 6 
The distribution of ex-ante asymmetry for one year risk premium forecasts

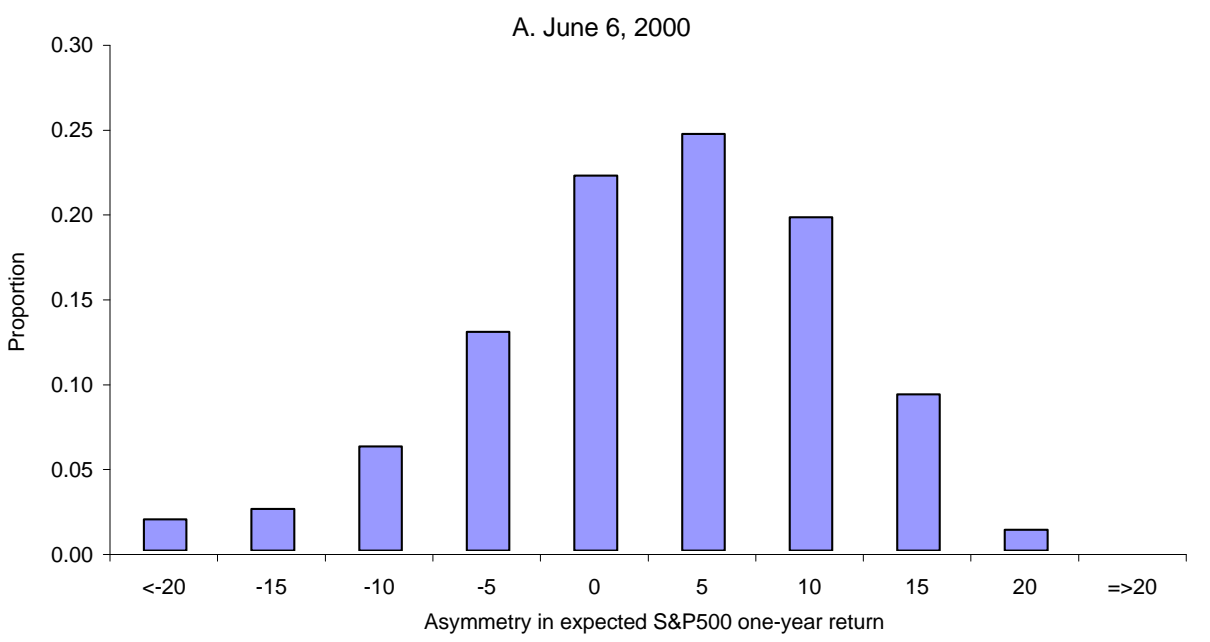

Average $=-0.83 \%$ Median $=0 \%$ Std. Dev. $=7.96 \%$

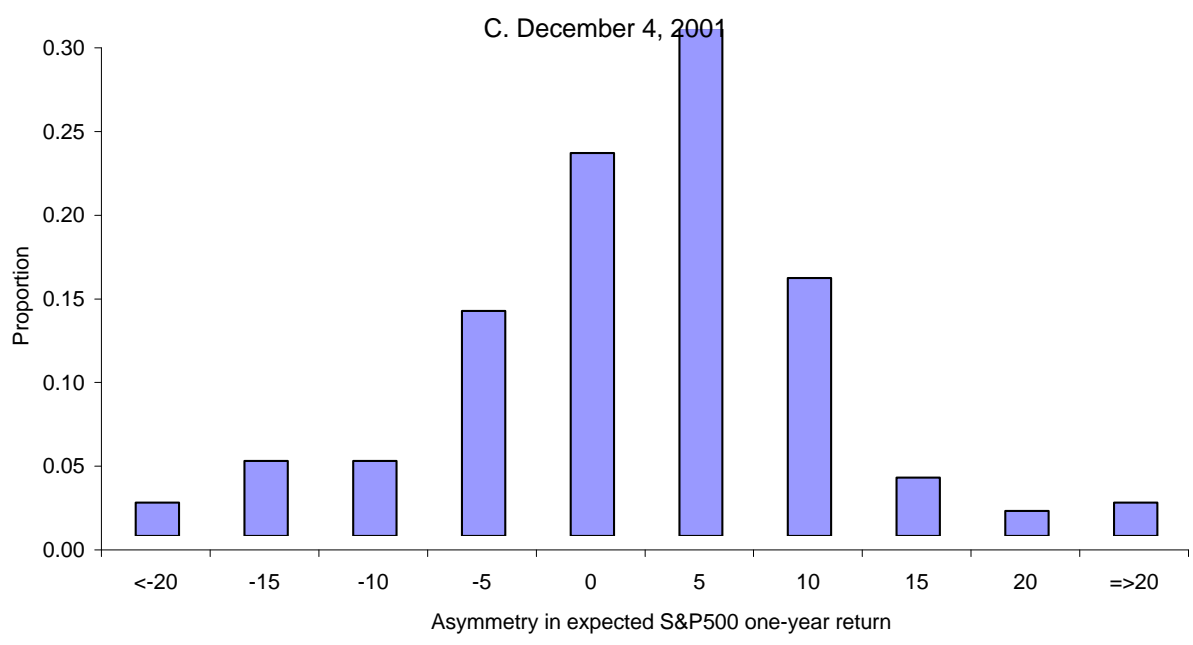

Average $=-1.41 \%$ Median $=0 \%$ Std. Dev. $=8.79 \%$

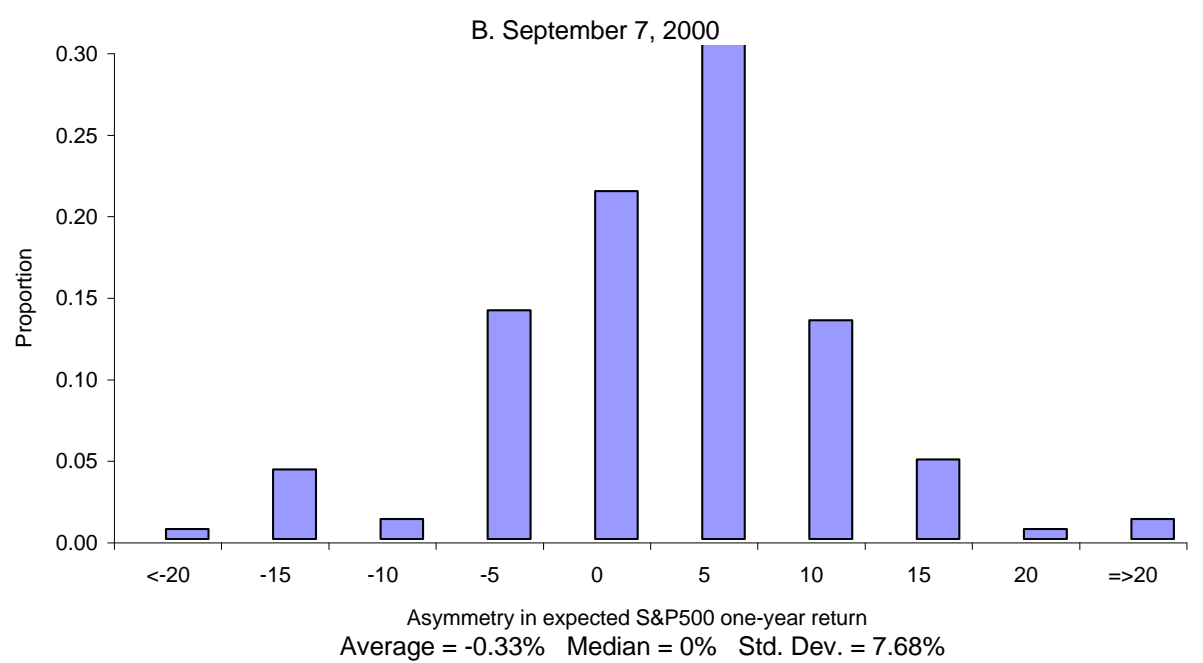

Average $=-0.33 \%$ Median $=0 \%$ Std. Dev. $=7.68 \%$

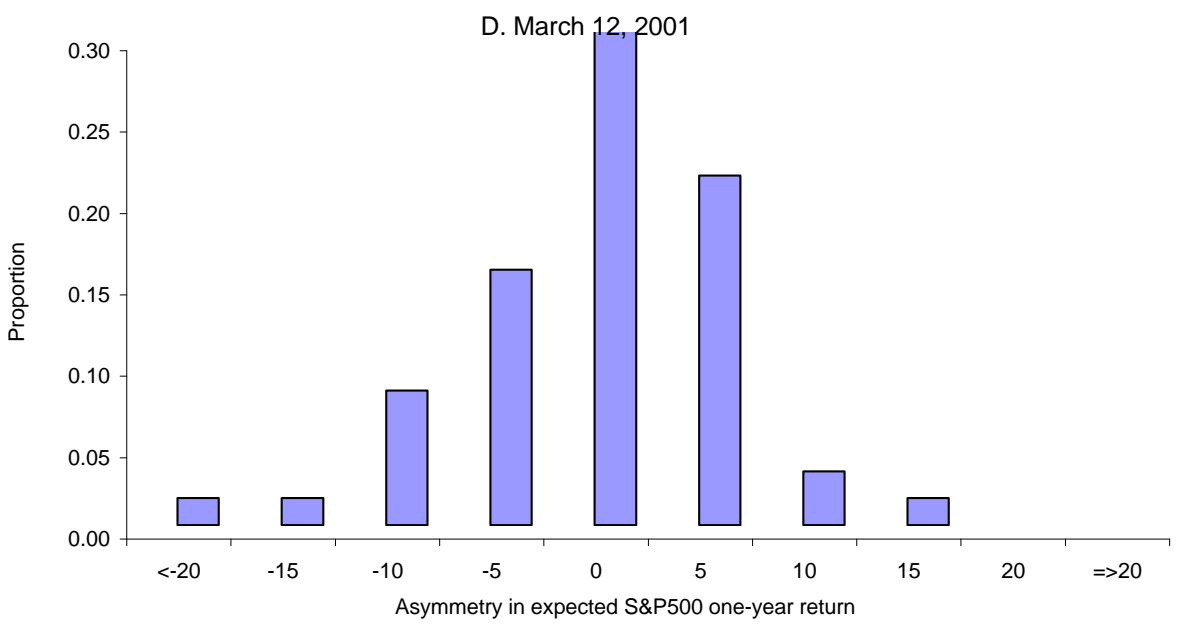

Average $=-4.05 \%$ Median $=-4.0 \%$ Std. Dev. $=6.39 \%$ 
The distribution of ex-ante asymmetry for one year risk premium forecasts

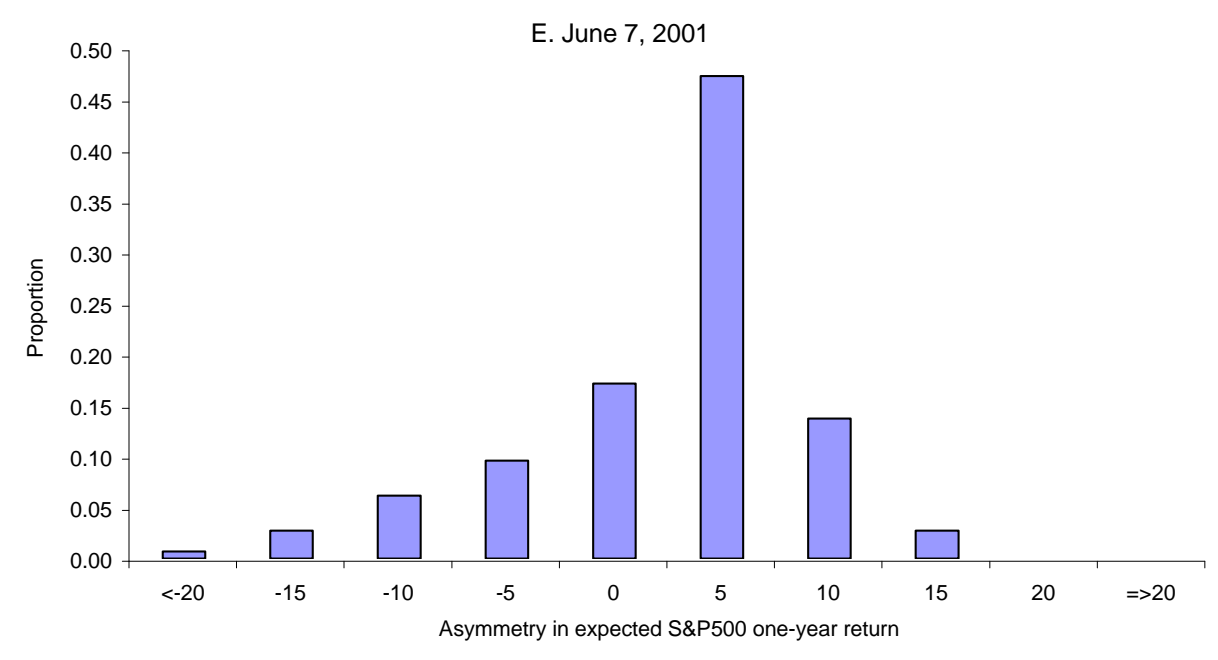

Average $=-1.12 \%$ Median $=0 \%$ Std. Dev. $=6.54 \%$

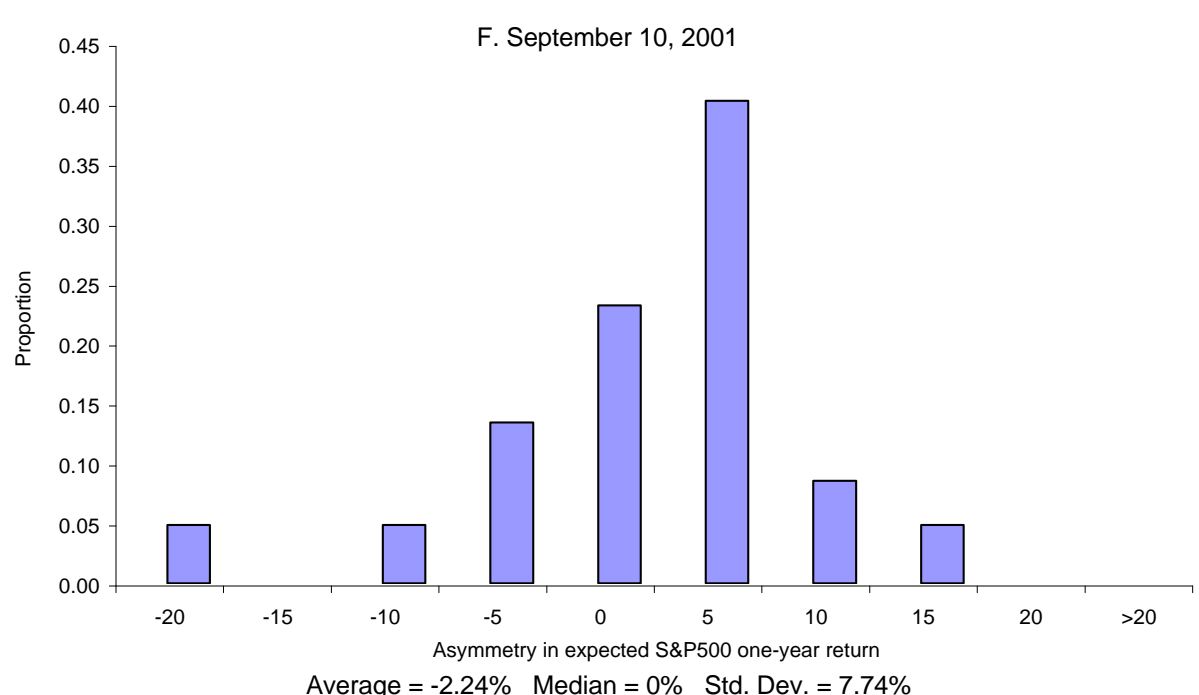

Average $=-2.24 \%$ Median $=0 \%$ Std. Dev. $=7.74 \%$ 
Recent returns and asymmetry

A. Asymmetry vs. market return

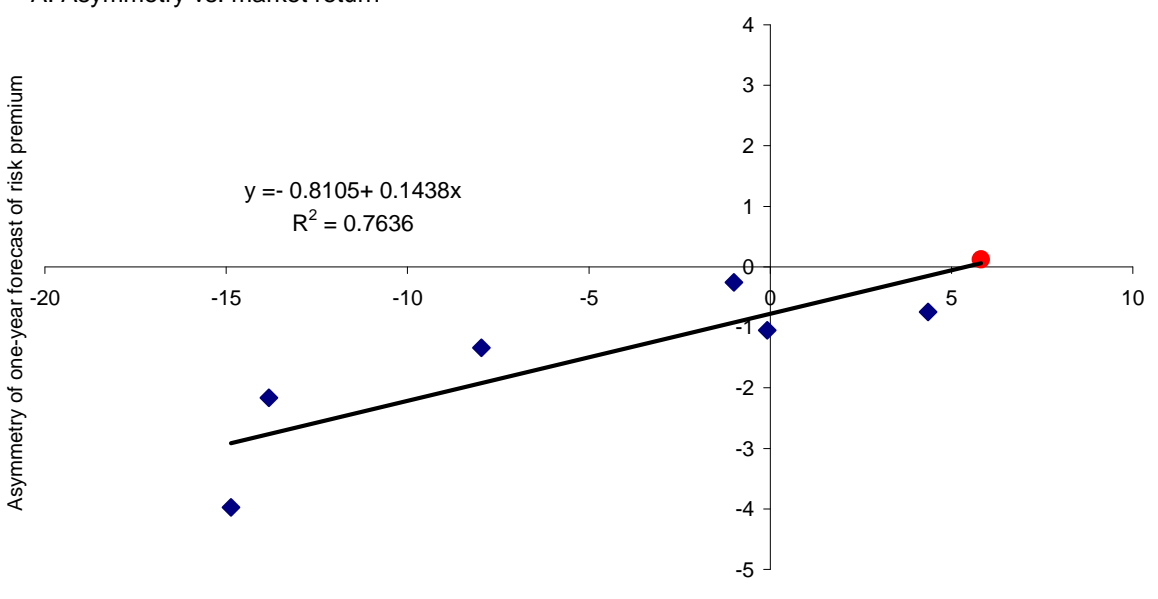

Excess market return for previous quarter

Fig. 8 
The relation between the risk premium and ex ante volatility

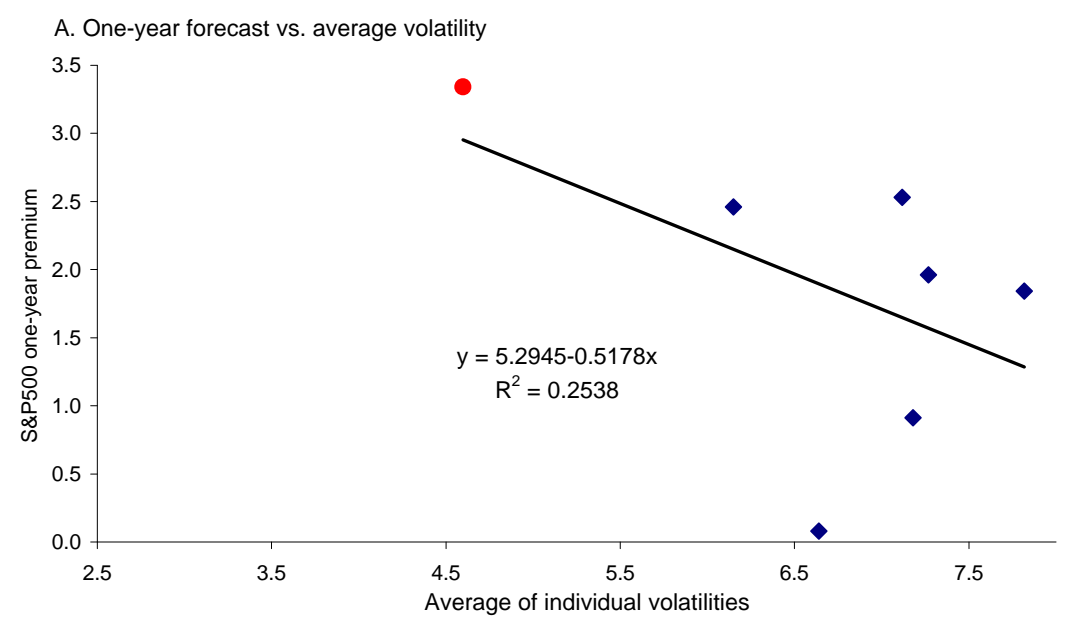

B. One-year forecast vs. standard deviation
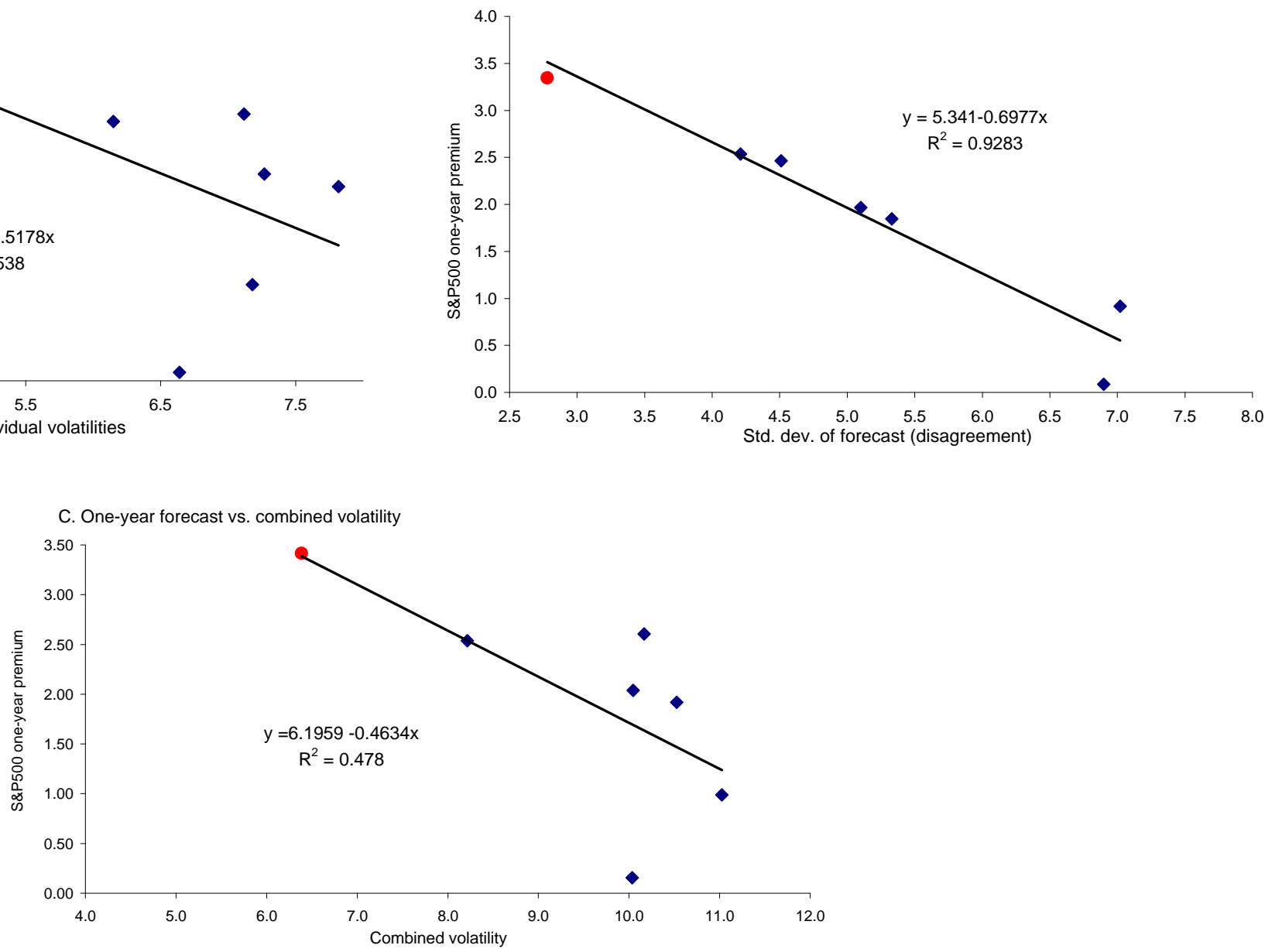

Fig. 9 


\section{The relation between the risk premium and ex ante volatility}
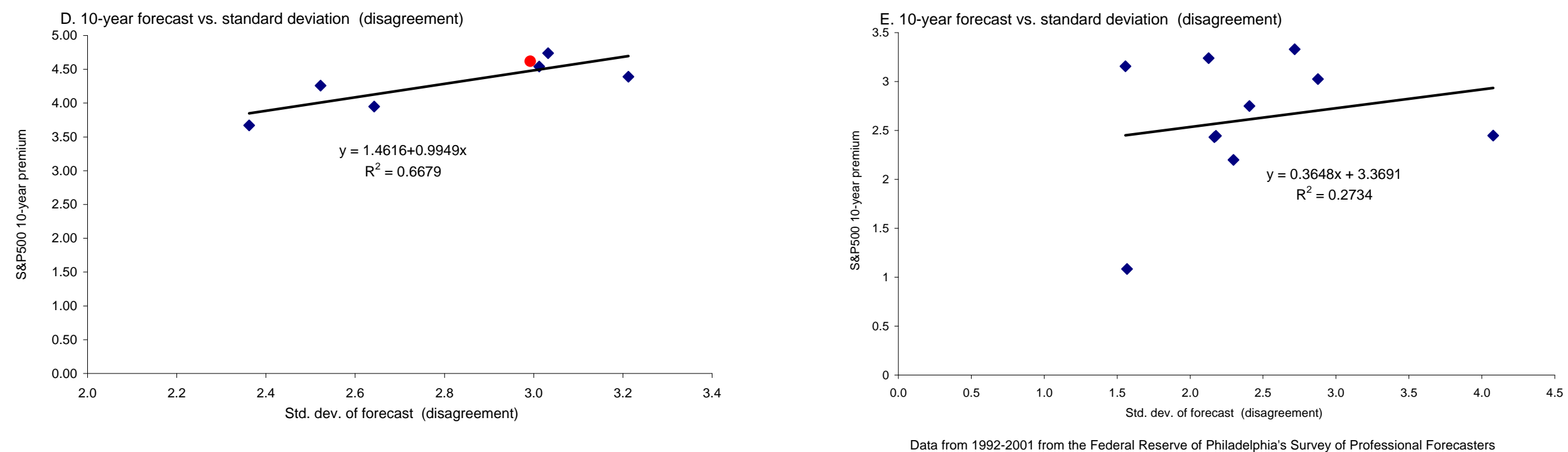

Fig. 9 (continued) 